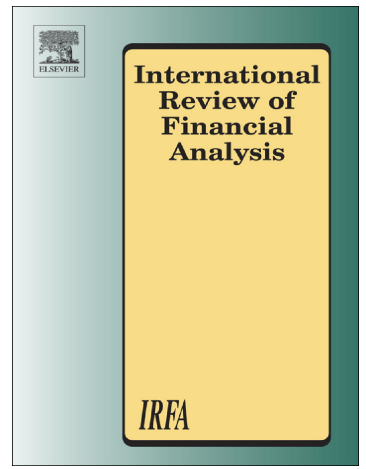

Sandra Betton, Frederick Davis, Thomas Walker

PII:

S1057-5219(18)30203-5

DOI: doi:10.1016/j.irfa.2018.03.013

Reference:

FINANA 1210

To appear in:

International Review of Financial Analysis

Received date:

6 October 2017

Revised date:

15 March 2018

Accepted date:

25 March 2018

Please cite this article as: Sandra Betton, Frederick Davis, Thomas Walker, Rumor rationales: The impact of message justification on article credibility. The address for the corresponding author was captured as affiliation for all authors. Please check if appropriate. Finana(2017), doi:10.1016/j.irfa.2018.03.013

This is a PDF file of an unedited manuscript that has been accepted for publication. As a service to our customers we are providing this early version of the manuscript. The manuscript will undergo copyediting, typesetting, and review of the resulting proof before it is published in its final form. Please note that during the production process errors may be discovered which could affect the content, and all legal disclaimers that apply to the journal pertain. 


\title{
Rumor rationales: The impact of message justification on article credibility
}

\author{
Sandra Betton, Frederick Davis, and Thomas Walker
}

\begin{abstract}
:
We perform content analysis on a unique sample of 2,074 first-instance published takeover rumors to study how the rationale underlying a publication relates to its credibility and its association with firm returns and rumor accuracy. While most takeover rumors are inaccurate, we find that distinguishing between various justifications of potential takeover activity as provided within the published article serves to predict takeover announcements, subsequent firm abnormal returns, and - to a lesser extent - premiums. In addition, we note a clear distinction in results based upon the informative versus speculative nature of the rumor. We interpret this evidence as supportive of our hypothesis that the underlying rationale justifying the release of public information affects firm share prices and aids in predictability.
\end{abstract}

JEL Classification codes: G14; G34; G30

* The authors would like to thank the Fonds Quebecois de la Recherche sur la Societe et la Culture (2015-NP-182891), the Social Sciences and Humanities Research Council (430-20130502), as well as Concordia University (seed funding program) for the funding of this research.

** All authors are affiliated with the John Molson School of Business, Concordia University, in Montreal, Canada. 
"News stories rarely have a simple, predictable effect on the market." - Shiller, 2005

Public news announcements are a major mechanism for disseminating information to investors, allowing them to estimate firm values (Tetlock, 2010, Engelberg and Parsons, 2011, Griffin et al., 2011). Dougal et al. (2012) and Peress (2014) report a market-wide impact of the media, while Ryan and Taffler (2004) find that corporate news events drive a significant proportion of economically significant price changes in the 350 largest firms on the London Stock Exchange. Despite the importance of the financial media, relatively few papers explore in detail how investors interpret descriptive information and whether they efficiently incorporate that information into prices, primarily due to the difficulty in objectively quantifying such information (Jegadeesh and Wu, 2013).

This article performs a rigorous content analysis of public news announcements in the context of takeover rumors. In particular, we quantify how the market responds to takeover rumors which are categorized according to the article's motivation; i.e. the underlying rationale(s) justifying the article's publication as provided in the initial ('scoop') news source. We further identify which of these rumor justifications are ultimately proven to be most accurate, in that the rumored target firm becomes subject to a formal takeover announcement within one year. Such rumors represent an appropriate setting to examine the underlying arguments upon which public information is based, as mergers and acquisitions impact a wide range of stakeholders and are among the biggest investment decisions a company ever makes (Luo, 2005); furthermore, takeovers on average result in offer premiums of over $46 \%$ (Betton, Eckbo, and Thorburn, 2009), with related rumors substantially responsible for price runups before a bid is formally announced (Betton et al., 2014).

Not all rumors in the business press provide similar information upon which investors can base their decisions. To illustrate, compare two unrelated articles, the first appearing in the New York Times on January 21, 2008, entitled "Getty Images up for Sale, Could Fetch \$1.5 Billion" 
which read: "Getty Images .... has put itself on the auction block and could fetch more than $\$ 1.5$ billion, people briefed on the situation said Sunday. The firm hired Goldman Sachs to advise it on a potential sale, these people said. The company has attracted interest from several buyers, mostly private equity firms, including Kohlberg Kravis Roberts, Bain Capital and others .... A spokeswoman for the company contacted last week said the company does not comment on 'rumors and speculation'." The second article, appearing in the Dow Jones Newswires on February 19, 2010, entitled “Options Report: Traders Quick to Respond to Buyout Rumors" noted that: "Options traders proved willing to respond to several buyout rumors Friday.... In Myriad Genetics, traders picked up 3000 calls and just 300 puts, taking particular interest in the company's March $\$ 24$ calls. Those contracts are priced at $\$ 0.45$ and make money if Myriad Genetics rises above $\$ 24.45$. The stock recently traded for $\$ 22.30$, gaining $3.3 \%$."

Rather than treating these takeover rumors as having equivalent investor outcomes, we code each rumor according to textual elements which relate to the underlying rationale for the rumor's existence. In the first article, the rumor article indicates an insider was cited, a financial advisor was hired, and private equity funds have expressed interest in the target firm. In the second article, the rationale for the rumor includes an increase in the number of call options placed on the target firm as well as unspecified pre-existing takeover chatter. We hypothesize that the nature of public information may differ in its immediate credibility and in its ultimate accuracy depending upon the underlying rationales justifying the rumor's publication. The coding of such rumor justifications provides in-depth clarification on the informativeness of publicly available signals and forms the basis for much of our empirical analysis.

We construct the largest database of first-instance takeover rumor articles to date, manually searching Capital IQ, Factiva, ProQuest, Standard \& Poor's Takeover Talk, and Zephyr to ultimately identify 2,074 "scoop" articles which first report a takeover rumor of a firm listed in the Center for Research in Security Prices (CRSP) database between 2002 and 2011. Once a takeover rumor is found that clearly identifies a target firm, we search backwards to ensure that a 
clean window of at least 180 days exists without similar rumors. We categorize rumors according to sixteen non-mutually exclusive takeover rationales as provided in the article text and note whether the rumor was denied by either the target firm, potential bidder, or both. We exclude rumors in which either the rumored bidder or target confirms that negotiations are underway to preserve a clear distinction between rumors and takeover announcements. We use the Thomson Reuters SDC Platinum database as the source of takeover announcement dates, but because results are heavily reliant on the existence and timing of such announcements, and SDC data accuracy has been heavily criticized (Bharadwaj and Shivdasani, 2003, Faccio and Masulis, 2005, Barnes et al., 2014, Mulherin and Simsir, 2015), we conduct a manual search of both Factiva and Google to correct for announcement date errors and omissions.

Through the use of takeover rumors, we investigate three main questions. First, which media article characteristics predict whether a rumor comes true? Second, do investors account for the characteristics that predict accuracy and which relate to future returns? Third, can investors combine signals available on the rumor date to predict outcomes? While our results arise from an analysis of takeover rumors, the benefits of analyzing article justifications and combined signals could be seen to apply to publicly available information in general.

To address our first question on the determinants of accuracy, we estimate a series of logit regressions of the likelihood that a rumor comes true on rumor content, with extensive controls for variables previously found to predict takeovers. These control variables include multiple proxies for managerial motivation to pursue a deal, target newsworthiness, abnormal returns surrounding the rumor date, and year, industry, and news article fixed effects.

To address our second question relating investor behavior to future outcomes, we first test whether the magnitude of the market's immediate response to a rumor predicts its accuracy. We then provide multivariate analysis of both rumored target firm and rumored bidding firm cumulative abnormal returns (CARs) surrounding the rumor date period. Furthermore, we 
construct long-short portfolios based on either the predicted accuracy of rumor characteristics or on a combination of rumor characteristics as available over the rumor date period.

To address our third question, we create two mutually exclusive categories of rumors based on the degree to which the rumor justification exhibits a demonstrable link to future takeover activity. In particular, we label as Speculative those rumors based solely on either takeover chatter or an increase in option activity in the target firm, with no further justification provided. Such rumors are often found in news sources such as Benzinga, The Fly on the Wall, or Street Insider, among others. We label as Informative those rumors based on at least three rumor justifications, excluding those labelled as speculative, hypothesizing that multiple takeover signal motivations will provide a stronger effect than one alone. This is similar in spirit to Kosfeld (2005, pp. 659) who asserts that "intensifying the communication increases the probability for agents to eventually believe in the rumour" and to Purnanandam and Seyhun (2017) who show that by following joint signals, there are significant gains in trading returns as compared to returns from trading strategies that only follow individual signals ${ }^{1}$. In essence, we create two simple and intuitive proxies of rumor credibility which are available to investors on the initial rumor date, and test for their relationship to accuracy and share price abnormal returns via a series of logistic and multivariate analyses.

A number of interesting results emerge from our investigation. First, we find that there are various rumor rationales which are significantly positive predictors of future takeover announcements and that are associated with significant rumored firm abnormal returns prior to, on, and after the rumor date. For example, takeover rumors citing the potential for unique synergetic benefits are predictive of takeover announcements and result in significantly positive pre-rumor date bidder firm returns, while takeover rumors based on target firm distress result in significantly negative rumor date target firm returns (and significantly positive rumor date bidder

\footnotetext{
${ }^{1}$ In fact, composite signals are commonly employed in finance, such as Altman's (1968) Z Score or Gompers et al. (2003) Corporate Governance Index.
} 
firm returns). These and other findings suggest that all takeover rumors should not be treated equally, as the literature often implicitly assumes, and in particular that the underlying justification for the rumor article has merit and deserves attention.

Second, we find that the magnitude of the market's response to the average rumor predicts the rumor's accuracy, but not fully. Many rumor characteristics remain significantly related to accuracy after controlling for the stock market's response, while the average target of a rumor experiences an abnormal return reversal, i.e. a rumor date overreaction, following the rumor publication. Surprisingly, rumor date underreaction also exists, particularly for rumors based on industry activity or for rumours citing the potential for unique synergetic benefits.

Third, not all takeover announcements are considered good news for target firms around the announcement date, and factors which predict takeover announcements in general are not identical to those which predict takeover announcements beneficial to target firms ${ }^{2}$. In particular, rumor date runup abnormal returns, $C A R(-5,-1)$, as well as rumors in which the target denies that takeover negotiations are underway, TargetDenied, are significant predictors of beneficial takeover announcements but not takeover announcements in general. This suggests that some investors have access to information contained within the initial rumor article shortly prior to its release, and can distinguish the share price effect this will have on the target firm.

Fourth, we find that Informative (Speculative) rumor rationales are significantly positive (negative) predictors of impending takeover announcements, and are significantly positively (negatively) related to rumor date target firm returns. These findings suggest that the degree to which the rumor is demonstrably linked to future takeover activity is important; in particular, rumors providing multiple signals of explained linkages (i.e., informative rumors) are not only more accurate than those providing vague linkages (i.e., speculative rumors), but are also deemed to be more credible on the rumor date, and more likely to result in abnormal return

\footnotetext{
${ }^{2}$ As defined by providing a positive cumulative abnormal return to the target firm over the $(-41,+1)$ takeover announcement period.
} 
continuations than reversals over the post-rumor period. Additionally, an equally-weighted portfolio which is long on target firms subject to Informative rumors and short on target firms subject to Speculative rumors provides $1.09 \%$ monthly returns over the one-year post-rumor period, significant at the $1 \%$ level. Similarly, an equally-weighted portfolio which is long on targets having rumor characteristics predictive of rumor accuracy and short on rumors with no significant prediction power provides statistically significant monthly returns of $1.06 \%$ over the following year ${ }^{3}$.

Fifth, we find that certain rumor types are associated with significantly positive bidder firm abnormal returns both prior to and during the rumor date period. Rumor dates are an average (median) 130.14 (98) days prior to any forthcoming takeover, supporting the viewpoint that bidder announcement period returns underestimate the wealth effects of bidding (Cai et al., 2011).

Finally, we contribute to the debate on the rumor effect on premiums: Chou et al. (2015) find a significantly positive effect, whereas Ahern and Sosyura (2015) do not. We find that the length of the runup period is important in order to ascertain the association: a longer runup incorporates substantially more initial target firm rumor publications. This increases returns over the runup period enough to offset decreases during the markup period, resulting in an overall insignificant association. However, rumors cited by an insider have a positive effect, whereas rumors initiated by the target have a negative effect.

Our study relates to a rapidly growing area of research on financial content analysis which quantifies the breadth, content, timing, and/or tone of descriptive public information and examines how the market interprets it. For example, Fang and Peress (2009) find that stocks with no media coverage earn higher returns than stocks with high media coverage, suggesting that the breadth of information dissemination affects stock returns; Tetlock (2011) finds that firms react

\footnotetext{
${ }^{3}$ Trading costs are not included in these calculations; additionally, illiquid stocks appear to be limiting arbitrage opportunities. 
less to stale news yet trade more aggressively on it; Guran and Butler (2012) find that news content varies systematically with the characteristics and conflicts of interest of the source; Tetlock (2007), Tetlock et al. (2008), Loughran and McDonald (2011), Jegadeesh and Wu (2013) and others find relationships between article tone and various measures of financial performance; and Chen et al. (2014) conduct a textual analysis of articles published on Seeking Alpha, a popular social media website, and find that the views expressed in both articles and commentaries predict future stock returns and earnings surprises.

Our paper also contributes to the literature on share price momentum and reversals. Daniel et al. (1998) model investor behavior based on overconfidence and biased self-attribution, with investors maintaining prior beliefs and discounting public signals, resulting in underreaction to public information; Barberis et al. (1998) present a model based on investor sentiment in which stock prices underreact to earnings announcements and similar events while overreacting to consistent patterns of good or bad news; Hong and Stein (1999) build a model with two types of rational agents, "newswatchers" and "momentum traders", finding both underreaction and overreaction from gradually diffusing news about fundamentals; Chan (2003) finds that stocks with bad news exhibit momentum while stocks experience reversals only if unaccompanied by public news; and Hoitash and Krishnan (2008) find that investors overreact for firms showing a high degree of speculative intensity. In finding an initial public announcement which leads to either underreaction or overreaction according to the justification provided for the rumor, our empirical results suggest article rationale as a contributing factor of share price momentum.

Finally, our paper relates to the empirical literature on takeover rumors. Zivney et al. (1996) use the "Abreast of the Market" (AOTM) column of the Wall Street Journal in addition to the HOTS column to find 302 initial rumor publications. They find that rumor date runups exist, which are substantially higher for those rumors turning out to be true. Moreover, they find that rumored target firms published in the AOTM column experience overreaction on the rumor date, giving rise to profitable investment opportunities. In a sample of 263 initial rumors, Chou et al. 
(2015) agree that trading on rumors can be profitable by virtue of utilizing pre-rumor day abnormal returns as a signal of rumor accuracy. In a sample of 519 initial takeover rumors over the period 2005-2011, Ma and Zhang (2016) find that investors overreact to acquisition rumors. Jia et al. (2017) find that market reaction and accuracy are related to tweet volume in a sample of 474 initial rumors over the period 2009-2014.

In the paper most similar to ours, Ahern and Sosyura (2015) provide a thorough analysis of 501 initial merger rumors from the Factiva database over the years 2000-2011. They make a substantial contribution to the literature, finding that target newsworthiness, journalist characteristics, article characteristics, and media sources are significantly related to rumor accuracy and rumor date returns. They also find that the market overreacts to the average merger rumor, while premiums remain unaffected. We find market reversal on the average merger rumor only when it is false, while the rumor's association with the premium depends on the length of the runup period employed.

Additionally, while they do examine certain article characteristics, such as the reported stage of the merger and the ambiguity of the language used in the article, they do not focus on the justification of the rumor message itself as we do (i.e. the sixteen rumor characteristics we identify, as well as our categorical groupings into a speculative and informative nature). We believe that this is critical, as these explain why the article was ostensibly written, presenting investors with the factual arguments underlying the rationale to publish the article. Investors can thus base their investment decisions on more than "just a rumor": they instead can base their investment decisions on the claims established within the rumor article, often having an opportunity to verify such claims (e.g., whether a block purchase of target shares did indeed occur, and whether it may represent a threat to corporate control; or whether a financial advisor specializing in mergers was indeed hired, and whether this hiring was indeed for purposes related to preparing the firm to be acquired). Rumor accuracy and stock returns may thus be reliably linked to the depth of information provided by the article. 
Unlike the aforementioned papers, we provide extensive controls for firm characteristics which have been commonly identified as determinants of takeover predictability (cf., Cornett et al., 2011), and appear to be the first paper to present bidder firm abnormal returns over the rumor date period. Furthermore, as we discuss in the following section, our data was meticulously collected in a manner which we believe is most likely to capture the initial takeover rumor, resulting in a sample size of 2,074 observations, approximately four to eight times the sample size of the abovementioned studies.

Examining takeover rumors within the business press, our paper is unique in its manual deconstruction of the signals that prompted the publication of the article, and in demonstrating the linkages between these signals and the resulting market responses to rumored target and bidder firms. In so doing, we provide new evidence on the determinants of accuracy and abnormal firm returns as related to information credibility in the business press.

\section{Data and Methodology}

This paper employs a market model approach in estimating firm abnormal returns ${ }^{4}$, as espoused by Campbell et al. (1997) and utilized in Aktas et al. (2004), Betton et al. (2014), and Chou et al. (2015), among others:

$R_{i t}=\alpha_{i}+\beta_{i} R_{m t}+u_{i t}$,

where $R_{i t}$ and $R_{m t}$ are the daily returns on stock $i$ and the CRSP value-weighted market portfolio on day $t, \alpha_{i}$ and $\beta_{i}$ are regression coefficients estimated over a 250 day period ending on day -43 relative to the event date, and $u_{i t}$ is a residual error term representing the abnormal return. Cumulative abnormal returns (CARs) are subsequently formed by aggregating abnormal returns across firms and over time.

\footnotetext{
${ }^{4}$ To ensure the robustness of our results, we also calculated market-adjusted CARs, as utilized by Ahern and Sosyura (2015), and employed these in our main analysis. The results are quantitatively and qualitatively very similar to our reported findings. The respective tables are not reported here for brevity, but are available from the authors upon request.
} 
We define takeover rumors as any conjecture published within newspapers, newswires, business journals, and/or trade journals which expressly indicate that a public firm contained within the Center for Research in Security Prices (CRSP) database is clearly a potential target of an impending merger or acquisition. Specific sources thoroughly investigated include the databases of S\&P Capital IQ, S\&P Takeover Talk, and Zephyr, as well as the online services of Factiva and Pro-Quest (which themselves include thousands of newswires and printed communications, including the Wall Street Journal, the Economist, Bloomberg Businessweek, and Dow Jones Newswires, among many others).

To uncover such rumors, we employ a proprietary algorithm by first investigating actual takeover rumors that are easily identifiable - those available in S\&P Takeover Talk, S\&P Capital IQ, and Zephyr. An initial sample of over 200 different takeover rumors thus provided the basis for developing an algorithm to search for additional takeover rumors contained within Factiva and Pro-Quest. The search algorithm contains terms such as "strategic alternative", "buyout", "sale of the firm", "looking to be acquired", "takeover candidate", and "takeover chatter", amongst others, in combination with Boolean logic and another set of terms such as merger, takeover, rumor, chatter, acqui*, etc.

We then utilize this proprietary algorithm to find articles in both Factiva and in Pro-Quest news sources not overlapping with Factiva (such as the Financial Times, Barron's, the Mergers \& Acquisitions Report, etc.). Because the algorithm results in many false positives, we manually distinguish articles containing takeover rumors from those which do not. We then use a second streamlined algorithm incorporating the target firm's name to identify any additional preceding rumors, stopping only when a clean window of at least 180 days was established. After aggregating results from all five databases investigated, we once again employ a Factiva search using our streamlined algorithm to ensure our clean window of 180 days is retained, losing many rumors in the process. 
Next, we code the rumor's content according to which of sixteen potential takeover rumor rationales were provided within the scoop article, additionally noting whether either the potential bidder or target denied that negotiations were underway. Appendix A summarizes the variable definitions. Rumors are further categorized as speculative if based solely on either takeover chatter or an increase in the number of call options placed on the target firm, and as informative if based on three or more non-speculative rationales. The latter classification accounts for prior findings that suggest that message credibility increases when multiple signals are present (Kosfeld, 2005) and when the signals themselves are more verifiable (Peterson, 2004). Speculative rumors provide no underlying connection to an impending takeover - nothing in the article explains why the takeover chatter exists, or why an increase in call options is attributed to an impending takeover rather than to optimism regarding firm prospects. In contrast, every other rumor type provides specific reasoning within the article that links the rationale directly to future takeover activity; we therefore expect increased takeover anticipation and better accuracy rates in such cases.

Finally, all rumor articles that reached this stage were re-read and their coding was verified by multiple researchers to ensure accuracy. To assist in determining associated announcement dates, we conducted a manual search of both Factiva and Google, correcting for 52 errors and 143 omissions found within SDC.

In sum, the utmost rigor was used to correctly identify and code the initial release of publicized takeover rumors from a wide variety of media sources, covering approximately 30,000 individual business publications, newspapers, and newswires over the ten-year period from 2002 to 2011. This has resulted in the largest sample size of scoop takeover articles to date, containing 2,074 initial takeover rumors of target firms, 714 of which also mention a rumored bidding firm, and 433 of which lead to a takeover announcement within one year of the scoop article. 
This rumor collection procedure contrasts to that taken by Ahern and Sosyura (2015) in a number of important ways: First, we believe that our sample is more likely to contain the initial ('scoop') article. We note that Ahern and Sosyura use only the 33 largest domestic newspapers in Factiva for the first pass of rumor collection, frequently only searching backwards one week for a more recent rumor version. However, we find that takeover rumors involving the same target firm can occur from a variety of different sources during the prior 180 days. This is critical in determining a precise market response. Second, to preserve a clear distinction between rumors and takeover announcements, we exclude rumors which are confirmed by the target firm, or which provide details of a specific bid price. In contrast, Ahern and Sosyura include such articles, with $38.6 \%$ of their sample rumors providing the specific takeover price offered. Third, we conduct a manual search of both Factiva and Google, correcting the aforementioned errors and omissions found within SDC. Finally, as presented in Table 1, our sample size is substantially larger (2,074 observations, compared to 501) and quite different from that of Ahern and Sosyura's: our rumored target firms are smaller in terms of size, Tobin's Q, advertising/assets, and $R \& D$ to assets ${ }^{5}$, yet the aggregate market value of our sample (11.1 trillion) compares favorably with theirs (having a lower bound of 6.6 trillion).

\section{Results}

\section{Summary statistics and univariate results}

Table 1, Panels A through C, presents summary statistics of rumored target firms. Overall, the number of scoop rumors trends upwards, with the years 2010 and 2011 resulting in more articles than the six years from 2002 to 2007. The accuracy rate indicates the percentage of initial rumor articles resulting in a formal takeover announcement within 365 days, and ranges from

\footnotetext{
${ }^{5}$ This is likely a consequence of having a clean window of 180 days for every rumor: very large firms are rarely free of takeover rumors for such an extended period of time.
} 
$9.8 \%$ for rumors based on takeover chatter to $44.3 \%$ for rumors in which an insider is cited as the source of the rumor.

On average, $20.9 \%$ of initial takeover rumors yield formal takeover announcements within one year, increasing to $27 \%$ within two years. In the short term, $9.8 \%$ (15\%) of initial rumors result in announcements within 90 (180) days (untabulated). Additionally, we see that informative rumors come true $37.6 \%$ of the time, versus a rate of only $6.7 \%$ for speculative rumors.

Cumulative abnormal returns in event time from 20 trading days before to 20 trading days after the rumor are presented in Table 2 and depicted in Figure 1. As shown in Panel A, overall rumor date $(0,+1)$ CARs are $3.81 \%$ (p-value $<0.001$ ), while accurate and non-accurate rumors yield significantly positive rumor date CARs of $8.37 \%$ and $2.62 \%$, respectively. The mean difference of $5.75 \%$ is significant at the $1 \%$ level, implying that investors are able to distinguish between accurate and non-accurate rumors on the rumor date ${ }^{6}$. This is true despite an average time to takeover announcement of 130.14 days for accurate rumors, and is consistent with the results of Ahern and Sosyura (2015).

This ability to distinguish accuracy extends to many but not all rumor types, with ten of the sixteen rumor rationales having significant positive abnormal return differences between accurate and non-accurate rumors. Rumors denied by the target firm result in accurate and nonaccurate rumor date CARs of $1.74 \%$ (non-significant) and $9.48 \%$ (significant at the 5\% level), respectively, with the difference of $-7.84 \%$ significant at the $10 \%$ level. Stated differently, investors appear to disbelieve target firm denials more so when such denials are in fact correct, and this is the only rumor category for which non-accurate scoop rumors outperform accurate scoop rumors on the rumor date.

\footnotetext{
${ }^{6}$ In unreported robustness checks, this significance level remains after removing rumors leading to takeovers within 30 days after the initial rumor, as a control for omitted signals investors may be using to predict rumor accuracy.
} 
Every rumor rationale except TargetDistress and UnusualActivity results, on average, in significant CARs over the rumor date $(0,+1)$, with FinancingSource and SynergyCited impacting target firm returns the most, having rumor date CARs of $10.25 \%$ and $9.04 \%$, respectively, each significant at the $1 \%$ level. Confirming our hypothesis that a demonstrable linkage to future takeover activity within the rumor affects takeover anticipation, we find rumor date CARs of $6.18 \%(1.80 \%)$ for Informative (Speculative) rumors, respectively, a difference significant at the $1 \%$ level in untabulated difference-in-mean analyses.

During the runup period to the rumor $(-20,-2)$, as presented in Panel B, initial rumors in aggregate are only associated with significant abnormal CARs (2.33\%) when they later prove to be accurate, and such returns are significantly different from non-accurate rumor runup returns (p-value $=0.012$ ). Similarly, investors distinguish rumor accuracy when the hiring of a financial advisor $(\mathrm{p}$-value $=0.007)$ or an insider $(\mathrm{p}$-value $=0.066)$ is cited as the basis for the rumor, consistent with information leakage arising from individuals with intimate knowledge of potential takeover negotiations (Agarwal and Nassar, 2012). We find significantly positive CARs for rumors citing an insider ( $\mathrm{p}$-value $=0.028$ ), potential synergies ( $\mathrm{p}$-value $=0.095)$, or based on unusual activity ( $\mathrm{p}$-value $=0.089$ ), and significantly negative CARs for rumors based on an increased number of call options on the target firm ( $\mathrm{p}$-value $=0.010$ ), undervaluation of the target firm ( $p$-value $=0.057$ ), denial from the rumored bidder ( $p$-value $=0.098$ ), or based on speculation ( $\mathrm{p}$-value $=0.059$ ). Such variation in runup period returns provides evidence that information leakage and/or the market's ability to otherwise anticipate takeovers varies by underlying characteristics within the rumor article.

During the post-rumor period, as shown in Panel C, we see that the market reverses its opinion of the average merger rumor only when it is indeed false ${ }^{7}(\mathrm{CAR}=-0.79 \%$; $\mathrm{p}$ value $=0.089$ ). Investors further demonstrate post-rumor aptitude by distinguishing between

\footnotetext{
${ }^{7}$ In unreported robustness checks that we perform for comparison purposes, the market reverses its opinion of the average merger rumor only when it is false over both the $(+1,+10)$ and $(+2,+10)$ post-rumor period.
} 
accurate and non-accurate rumors correctly when the underlying rumor rationale involves large share purchases $(\mathrm{CAR}=6.6 \%$; $\mathrm{p}$-value $=0.078)$, private equity fund involvement $(\mathrm{CAR}=3.13 \%$; $\mathrm{p}$ value $=0.089)$, or target firm undervaluation $(C A R=5.11 \%$; -value $=0.093)$. We further find a strong market reversal for rumors based on takeover chatter $(\mathrm{CAR}=-2.66 \%$; $\mathrm{p}$-value $<0.001)$, whereas we see evidence of rumor date underreaction for rumors based on the involvement of a private equity fund $(\mathrm{CAR}=1.75 \% ; \mathrm{p}$-value $=0.035)$.

Panel D displays CARs over the $(-20,+20)$ rumor period, demonstrating that in aggregate and for many rumor rationales, investors are, once again, able to distinguish between accurate and non-accurate rumors, with a significantly positive CAR differential of $11.03 \%$ (pvalue $<0.001)$.

In sum, our univariate results provide substantial evidence that firm returns differ according to rumor accuracy. However, such investor acumen is not evident with respect to all types of rumors, particularly when the target firm's management denies the rumor. The importance of the underlying rumor rationale is further delineated by the variation in abnormal rumor date returns, ranging from $10.25 \%$ for rumors mentioning the potential source of financing to $-0.72 \%$ for those indicating that the takeover stems from target firm distress. In addition, we show that rumors labelled Speculative provide significantly lower abnormal returns than those labelled Informative in each of the time periods examined. Indeed, informative rumors outperform speculative rumors by $3.56 \%$ (p-value $=0.005)$ in the $(+2,+20)$ post-rumor period, with investors having the opportunity to classify rumors and set their trading strategy on the rumor date. Overall, this evidence is consistent with investors interpreting the likelihood of a takeover differently based on the perceived quality of the signals identified in the initial rumor content. We next look for confirmation of our findings in a multivariate regression context.

\section{Target firm returns on the rumor date $(0,+1)$ : Multivariate results}


We next examine whether stock price responses to target firm scoop rumors are associated with rumor content after controlling for alternative explanations. Following Ahern and Sosyura (2015), we use the following controls: news article fixed effects to account for the influence of the publication on investors' belief in the rumor's accuracy; the cumulative abnormal returns of the target in the five trading days prior to the rumor's publication, $C A R(-5,-1)$, to control for staleness and information leakage; an indicator of newsworthiness, ValuableBrand, to control for rumor sensationalism designed to generate audience attention; and an estimate of the eventual target firm announcement return if the rumor does indeed come true, EstAnnReturn, to control for investors' potential reward.

News article fixed effects are created using all media sources providing at least five scoop articles, while ValuableBrand is a dummy variable representing target firm inclusion in a list of the top 100 brands from the marketing consultancy firms Interbrand and BrandZ anytime between 2002 and 2011. EstAnnReturn is estimated from a linear regression of target announcement day returns on target size, industry, and year fixed effects in a sample of 2,342 official merger announcements of public targets over the period from 2002 to 2011 as provided by the SDC database.

Because investors may base their belief in rumor accuracy on underlying firm characteristics rather than on rumor details, we follow Cornett et al. (2011) who predict target firm takeover candidacy using variables which measure management's motives to generate shareholder value, opportunistic benefits, or both. As mergers may be motivated by management's desire to withstand economic disturbances, Salesshock is defined as the absolute value of the difference between the two-year median industry sales growth rate and the two-year median sales growth rate of all sample target firms (Mitchell and Mulherin, 1996). To account for convexity, we also use the square of sales shock (Salesshock sq). Changesize2y, the percentage change in the firm's total assets over the previous two years, and Salesgrowth2y, the percentage change in the firm's sales over the previous two years, are used to proxy for 
economies of scale or scope (Gort, 1969, Palepu, 1986, Ambrose and Megginson, 1992, and Moeller et al., 2004). Concentration, the ratio of sales of the largest four firms to total three-digit SIC industry sales, measures barriers to entry and thus the need for mergers to survive (Gort, 1969, Eckbo, 1992).

Representing management motives to access new sources of capital, Resmismatch is a dummy variable equal to one if i) sales growth for a firm in the last two years is less than the industry median and the long-term debt ratio (the ratio of the book value of long-term debt to total assets) is greater than the industry median, or ii) if sales growth in the last two years is greater than the industry median and the long-term debt ratio is less than the industry median, and zero otherwise (Palepu, 1986, Ambrose and Megginson, 1992). ROA, calculated as the ratio of net income before extraordinary (or nonrecurring) items to total assets, represents firm profitability as a merger motive, while Shareturnover, the ratio of the number of shares of stock traded for the firm to total shares outstanding, proxies for discrepancies in valuation which can prompt mergers (Gort, 1969, Rhodes-Kropf and Viswanathan, 2004). Cashratio, the ratio of cash and marketable securities to marketable assets, accounts for the hypothesis that firms with more cash are more likely to propose bids (Harford, 1999, Harford et al., 2008) than receive them.

With research indicating that firms with a history of mergers are more likely to receive additional bids (Schipper and Thompson, 1983, Asquith et al., 1983, Malatesta and Thomson, 1985, Loderer and Martin, 1990, Holmes and Schmit, 1995, Fuller et al., 2002, and Ismail, 2005), Prevmergers counts the number of times a firm proposes or receives a merger bid in the prior two years. Dormancy, the number of months since the last merger in the same three-digit SIC industry, represents merger intensity, with low values indicating a greater likelihood for the target to participate in the merger wave (Song and Walkling, 2000, 2011). Priorreturn2y and Infoasymm measure management's motives to exploit its information advantage when markets misprice firm value (Hansen, 1987, Schwert, 1996, and Betton et al., 2008). Priorreturn2y is the change in a firm's stock price in the two years prior to a given quarter, while Infoasymm is a 
dummy variable equal to one if a firm's stock price is both overvalued (with a market-to-book value greater than the industry median) and opaque (share turnover is lower than the industry median). Finally, we also control for the cumulative abnormal returns of the target 41 trading days prior to the rumor's publication as Chou et al. (2015) find this to be a determinant of future takeover announcements.

Table 3 presents target firm CARs over the $(0,+1)$ rumor date period, using rumor characteristics as explanatory variables while controlling for industry, news, and year fixed effects, as well as firm fixed effects in Models 1,3 , and $4^{8}$. In Model 1, we find evidence of significantly positive CARs for rumors which indicate a financial advisor has been hired (pvalue $=0.009)$, incorporate the name of the potential bidder $(\mathrm{p}$-value $<0.001)$, or cite an insider as the source of the rumor ( $\mathrm{p}$-value=0.028). In contrast, we find evidence of significantly negative CARs in rumors based on analyst opinions ( $p$-value $=0.082)$ and target firm distress ( $p$ value $=0.005$ ), indicating a stark disparity in investor responses related to the underlying rationale.

In untabulated results, we see some support for ROA (p-value=0.035) and Salesshock (pvalue $=0.088$ ) positively influencing rumor date returns, and Prevmergers negatively influencing them (p-value=0.078). Additionally, we examine the news article fixed effects and find the Associated Press, Reuters Newswires, and the Wall Street Journal having significantly positive CARs of $0.027(\mathrm{p}$-value=0.065), $0.029(\mathrm{p}$-value<0.001), and $0.019(\mathrm{p}$-value=0.054), respectively, while Businessweek has significantly negative CARs of -0.020 (p-value=0.028).

In Model 2 we again categorize rumor content into Informative and Speculative rationales, expecting rumors which provide multiple direct linkages to future takeover activity to outperform those based on tenuous linkages. Indeed, this proves to be the case, with Informative CARs significantly positive and Speculative CARs significantly negative, at the $1 \%$ and $5 \%$

\footnotetext{
${ }^{8}$ Note that because EstAnnReturn is estimated using firm size, industry, and year fixed effects, these variables are omitted from Models 1, 3, and 4 (cf., Ahern and Sosyura, 2015).
} 
level, respectively. Moreover, these variables maintain their significance in Models 3 and 4 when further control variables are added. Model 4 includes the accuracy of the rumor, which is positively significant at the $1 \%$ level and confirms our univariate results that suggest that accuracy is, at least in part, identified by investors on the rumor date.

It is conceivable that over the rumor period, other takeover signals exist which we are unaware of yet which drive the rumor date returns. As this is more likely the case when takeovers are imminent, we perform a robustness test in which we remove 75 observations in which the announcement is forthcoming within the next 14 days. The results (unreported for brevity) remain qualitatively unchanged except for AnalystReport (p-value=0.181) which loses its significance in Model 1 and Speculative ( $\mathrm{p}$-value=0.053) which drops in significance in Model 4.

In sum, we interpret our results over the $(0,+1)$ initial rumor date period as consistent with investors treating initial takeover rumors differently dependant on the rumor content, particularly when rumors indicate that a financial advisor was hired, when they mention a potential bidder, cite an insider, or indicate target firm distress. With the exception of ROA and Salesshock, investors appear to value rumor content takeover signals on the rumor date over controls derived from the literature - that is, variables related to management motives for a takeover, firm newsworthiness as indicated by brand value, and the estimated announcement return. In addition, investors appear to disbelieve rumors which do not provide a definite linkage to the rationale for the takeover, yet believe those that provide multiple such linkages. Investor perceptions are often correct, with abnormal returns on accurate rumors significantly higher than those on inaccurate rumors. Any trading strategy predicated on takeover rumors may therefore be spurious if the information content of the rumor, in particular the rumor rationale, is not incorporated. 


\section{Accuracy}

We next employ a series of logistic regressions to predict which rumors result in a takeover announcement within 365 calendar days after the initial scoop article ${ }^{9}$. To control for investor takeover expectations, we use either rumor date returns or EstDealLikelihood. This latter variable represents the estimated probability that the deal comes true and is derived from acknowledging that the rumor date return $\left(\mathrm{R}_{0}\right)$ has two components: the probability the rumor comes true $(p)$, and the expected announcement return of the target firm if it does come true $\left(R_{a}\right)$. Rearranging the expression as $p=\mathrm{R}_{0} / \mathrm{R}_{\mathrm{a}}$ allows us to estimate $p$ using rumor date returns and our previous estimate of target announcement date returns, EstAnnReturn (Bhagat et al., 2005, Ahern and Sosyura, 2015).

Model 1 in Panel A of Table 4 shows that many rumor rationales are significantly positive predictors of subsequent takeovers, with AdvisorHired, BidderMentioned, InsiderCited, MgmtConcerns, SynergyCited, TargetDistress, TargetInitiated, and UnusualActivity all significant at the $5 \%$ level or better. The results scarcely differ in Model 2 in which EstDealLikelihood, the component of rumor date returns related to the accuracy of the rumor, is used as an independent variable in place of the rumor date returns, itself significant at the $1 \%$ level. Models 3 and 4 present results for categories of rumors, in which we show that Informative rumors are significantly positive predictors, while Speculative rumors are significantly negative predictors of takeover likelihood, at the $5 \%$ level or better in each model. In untabulated results of news article fixed effects in Model 1, only the Associated Press, the Financial Wire, and Street Insider are significant predictors, having coefficients of 0.731 (p-value=0.005), 1.278 (pvalue $=0.016)$, and $0.659(\mathrm{p}$-value=0.060), respectively.

\footnotetext{
${ }^{9}$ Our findings are qualitatively similar when we use 180 days or two years instead. The respective results are available upon request.
} 
Consistent with Ahern and Sosyura (2015), we find that the rumor date return, $\operatorname{CAR}(0,+1)$, is the most economically significant predictor of future target firm takeover activity ${ }^{10}$, while rumors involving noteworthy firms, ValuableBrand, are significantly less likely to be true, supporting the notion of rumor generation for the purpose of attracting readership. Additionally, our results concur with Palepu (1986) and others who find that target firm size is a negative predictor of takeover activity, as various transaction costs associated with the absorption of the target firm into the acquirer increase with the size of the target firm. In untabulated results we find a significantly negative coefficient on Shareturnover ( $\mathrm{p}$-value=0.008), contrasting with Gort (1969), and Cornett et al. (2011), who surmise that increasing discrepancies of opinion should lead to more mergers. Likewise, rather than reallocating resources to withstand economic disturbances as the literature suggests (Gort, 1969, Mitchell and Mulherin, 1996, Maksimovic and Phillips, 2001, and Andrade et al., 2001), we find a significantly negative coefficient on SalesShock $(\mathrm{p}$-value=0.005), although this latter result is no longer significant when we examine predictors of takeover announcements that are beneficial for target firms, discussed subsequently.

We perform robustness checks by considering a subsample of rumors in which we remove 75 observations in which the announcement is forthcoming within the next 14 days, as done earlier for Table 3. Again, the results (unreported) are qualitatively similar, with notable differences including BidderMentioned losing significance in both Models 1 and 2, while both TargetInitiated and Undervalued increase in significance (from the $10 \%$ to the 5\% level) in Model 2.

One subtlety associated with predicting takeover announcements is the common assumption that target firms experience positive CARs on the announcement date; however, this is not always the case, with only $53.7 \%$ of our accurate rumors leading to positive target firm CARs over the $(-41,+2)$ announcement day period. For comparison purposes, it is thus

\footnotetext{
${ }^{10}$ When considered alone, however, the $\operatorname{CAR}(0,+1)$ only provides a pseudo $\mathrm{R}^{2}$ of 0.037 .
} 
interesting to see how well rumor variables predict such 'beneficial' takeover announcements, as presented in Panel B of Table 4. While most results are qualitatively similar to Panel A, throughout Models 1 - 2 BidderMentioned, TargetDistress, TargetInitiated, and Undervalued are no longer significant, implying that takeover announcements arising from such rumors are either predicted well in advance of the announcement date, or not interpreted by investors as good news for the target firm. This latter viewpoint is supported by Masulis and Simsir (2017) and Davis, Walker, and Zhou (2017), who find that targets initiating takeover negotiations or experiencing distress perform poorly on the takeover announcement date.

Prior five-day returns and 41-day returns are now statistically significant predictors at the $5 \%$ and $1 \%$ level, respectively, in each model employed. This implies that some investors are not only aware of the impending rumor, but also that they are able to distinguish between rumors that are ultimately beneficial for the target firm versus those which are not. In unreported results, we confirm this by performing a two-sample t-test using unequal variances, finding that prior five-day (41-day) returns are $4.34 \%$ (7.44\%) higher for rumors leading to positive announcements than for rumors leading to non-positive announcements.

We also find that rumors that are denied by the target firm are useful in predicting beneficial announcements, but not announcements overall ${ }^{11}$. In untabulated results of news article fixed effects in Model 1, only the Associated Press is significant at the 5\% level or better, having a coefficient of 0.960 (p-value $=0.002)$.

In sum, our logistic regressions confirm that while most takeover rumors should not be believed, some rumor types are positive predictors of future takeover announcements, even in the presence of takeover predictability control variables and including year, industry, and news article fixed effects. In particular, we find that AdvisorHired, InsiderCited, MgmtConcerns, UnusualActivity and Informative rumors are consistently significant positive predictors, while

\footnotetext{
${ }^{11}$ Only six of fourteen rumors denied by the target firm lead to a takeover announcement, limiting further analysis.
} 
Speculative rumors are significant negative predictors, results which are robust to considering only 'beneficial' announcements and, in untabulated analyses, to removing observations which represent imminent announcements (those occurring within the next 21 days).

Our empirical evidence thus supports our central premises: the underlying rationale of the takeover rumor is an important predictor of rumor accuracy, with rumors combining multiple demonstrable linkages to future takeover activity being positive predictors of takeover announcements, and rumors providing only tenuous linkages being negative such predictors. This suggests that message justification should be of interest to both academics and practitioners in predicting future takeover activity.

\section{Trading strategies}

We form long-short portfolios of target firms in Table 5. The first row, labelled Rumor Characteristics, presents results based on the predicted accuracy of the rumor using the empirical models presented in Column 1 of Panel A in Table 4 (long target firms with significantly accurate rumor rationales, short those with no significant predictive power, excluding those with non-mutually exclusive rumor rationales), while the second row, labelled Rumor Informativeness, presents results based on the nature of the rumor's linkage to future takeover activity (long target firms with Informative rumor rationales, short target firms with Speculative rumor rationales). The first day a firm can be placed in a portfolio is day 2 after an initial rumor is published, and firms are held in the portfolio for up to one year after the rumor date, with daily portfolio rebalancing using equal weights.

Not accounting for transaction costs, we find economically and statistically significant positive returns on each portfolio as shown in Column 1, suggesting that the market does not 
fully account for all available information provided on the rumor date ${ }^{12}$. Such long-run abnormal returns imply a lack of arbitrage (Shleifer and Vishny, 1997); to confirm, we follow Ahern and Sosyura (2015) and partition our sample according to above- and below-median subsamples based on Amihud illiquidity, a proxy for the cost of arbitrage, and on a widely-used measure of liquidity, the proportional bid-ask spread. Indeed, we find excess returns to be significant primarily (although not exclusively) in the illiquid portfolio subsamples, confirming the supposition that limits to arbitrage are impeding market efficiency.

In sum, there appears ample evidence that post-rumor abnormal returns differ according to rumor content as presented in the initial scoop article. Rumors providing multiple substantive takeover rationales result in significantly positive abnormal returns, in direct contrast to rumors based solely on unsubstantiated takeover chatter or on increased purchases of call options. This finding is robust when considering a wide variety of time periods and methodologies in calculating abnormal returns. It appears that investors distinguish amongst rumor rationales with regards to their anticipatory ability and overall expected economic impact on the firm, and that multiple informative signals are deemed more credible and result in higher post-rumor returns than unsubstantiated rumors. Such findings suggest that forming a portfolio of rumored takeover targets without regard to implicit takeover rationales is inefficient - filling a gap in the extant literature which fails to identify the rationales provided for the rumors' existence, and predominately treats all rumors equally.

\section{Multivariate returns of rumored bidder firms}

Within our dataset of 2,074 initial articles on target firms rumored to be takeover targets, 895 specifically mention a potential bidder's name. Of these, 155 mention a second potential bidder's name and of these, 28 indicate a third potential bidder. However, many of these are not

\footnotetext{
${ }^{12}$ Note that the Rumor Characteristics portfolio is not an implementable trading strategy as its formation requires future information unavailable to an investor, while the Rumor Informativeness portfolio is implementable based on public information over the $(0,+1)$ rumor date period.
} 
publicly listed companies, and after matching data to CRSP (Compustat) we are left with 714 (568) rumored bidder observations, for which the average rumor date $(0,+1)$ CAR is a nonsignificant negative $0.031 \%$ ( $\mathrm{p}$-value $=0.806$ ). As all observations in this subsample mention a potential bidder, the 'speculative' category of rumors is non-existent.

To aid our analysis, we construct the rumored bidder's estimated announcement return in a manner similar to that of the target's estimated announcement return. Specifically, we regress bidder announcement day returns on bidder size, industry, and year fixed effects in a sample of 2,342 official merger announcements as provided by the SDC database over the period from 2002 to 2011 . We use the coefficients from this model to fit estimates of the announcement date bidder return (EstAnnReturn_B) for each rumored bidder return in our subsample ${ }^{13}$.

We present results for a multivariate analysis of rumored bidder firm cumulative abnormal returns over various rumor date periods in Table 6, with Model 1 presenting results over the (-20, -2) pre-rumor period. Here we see that SynergyCited is significantly positively associated with CARs at the $5 \%$ level, consistent with capturing synergies as a motive for acquisitions (e.g., Bradley et al., 1988; Rohdes-Kropf et al., 2005). It is unclear why BlockPurchase and TakeoverChatter are also significantly positively associated with CARs at the 5\% level. If rumored bidding firms are the ones purchasing the block of target shares, the former result may reflect the benefits such toeholds can provide to acquirers (Betton et al., 2009), while takeover chatter may be specifically generated by those enthusiastically desiring takeovers deemed desirable for the bidding firm; however, these suppositions merit further investigation.

Examining rumor date period $(0,+1)$ CARs in Model 2, we find that rumors indicating target firm distress result in significantly positive bidder firm returns at the $5 \%$ level. Positive target sales shocks, Salesshock, have a significantly negative correlation with bidder returns, while the largest economic impact to bidder rumor date returns occurs when the target firm has

\footnotetext{
${ }^{13}$ Note that because EstAnnReturn_B is estimated using firm size, industry, and year fixed effects, these variables are omitted from the regression, as was done for EstAnnReturn earlier.
} 
experienced a large sales shock, SalesshockSq, $(\mathrm{CAR}=0.12$; $\mathrm{p}$-value=0.012). Taken together, this implies that rumored bidders of distressed firms tend to do well on the rumor date, supporting the proposition that bidders perform well when acquiring targets in distress (Masulis and Simsir, 2017; Davis et al., 2017). Additionally, we find significantly positive returns when the rumor mentions private equity firm involvement $(\mathrm{CAR}=0.014$; $\mathrm{p}$-value $=0.024)$, which may indicate an investor belief that such professional industry involvement provides a signal that the potential acquisition is in the best interest of acquiring firm shareholders.

The significantly negative association between rumor date returns and FinancingSource may indicate that investors oppose the rumored method of financing the potential deal, or perhaps that investors oppose the takeover regardless of financing while deeming such a rumor type as a credible takeover indicator; alternatively, our results may simply reflect the effects of a strategy which shorts potential bidders who use stock as a method of consideration (Mitchell et al., 2004).

We note that significantly positive CARs for various categories of takeovers surrounding the rumor period corroborate the contention of Cai et al. (2011) that bidder announcement period returns underestimate the wealth effects of bidding.

\section{Rumor effect on premiums}

Much research finds a significant target firm share appreciation ('runup') prior to takeover bid announcements (Betton et al., 2008). From an efficient markets perspective, the runup reflects actual changes in firm value and thus impending takeover bids should rise equivalently (the markup pricing hypothesis). An alternate point of view is that the runup merely reflects the market's anticipation of an impending takeover bid, and thus bids should be independent of such changes in share price (the substitution hypothesis ${ }^{14}$ ).

\footnotetext{
${ }^{14}$ See Schwert (1996), Betton et al. (2014) and Chou et al. (2015) for insightful discussions on these hypotheses.
} 
Within this context, both Ahern and Sosyura (2015) and Chou et al. (2015) analyze 167 and 85 announcement premiums of rumored targets, respectively, defining the premium as the cumulative abnormal return of a period which combines both the runup window of $(-42,-1)$ with a subsequent 'markup' period as per Schwert (1996). While each paper finds that rumors positively impact the runup, Chou et al. find that rumors positively affect the total premium paid, while Ahern and Sosyura find no contribution at all due to the negative impact rumors have on the markup.

We perform a similar analysis, combining a sample of 433 takeover announcements of rumored targets together with the full sample of official SDC merger bids for public U.S. targets announced in 2002-2011 seeking a change in majority ownership. With day 0 representing the takeover announcement date, we define the runup as the CAR over the $(-42,-1)$ period, the markup as the CAR over the $(0,5)$ period, and consequently the premium as the CAR over the ($42,+5)$ period, in a manner identical to Ahern and Sosyura ${ }^{15}$. For robustness, we additionally compute the premium as the final offer price recorded in SDC compared to the price 42 days prior, truncating values at $-100 \%$ and $200 \%$, with missing premiums approximated using the ($42,+1)$ announcement return, in a manner similar to Officer (2003) and Jenter and Lewellen (2015), among others. Most control variables are consistent with Ahern and Sosyura (2015) ${ }^{16}$, while acquirer and target termination fees, the acquirer's public status, deal attitude, and the return on assets are motivated by Officer (2003), Betton et al. (2008), Moeller et al. (2003), and Dimopoulos and Sacchetto (2014), respectively.

Models 1-3 of Table 7, Panel A, display OLS regression results for the runup, markup, and combined premium periods, respectively. Contrary to prior studies, rumors are not found to

\footnotetext{
${ }^{15}$ While this markup window is shorter than that examined by Chou et al. (2015) and Schwert (1996), Ahern and Sosyura (2015) note that the vast majority of returns occur within the first few days after the bid announcement, and Betton et al. (2014) also prefer shorter markup windows to minimize the effect of subsequent events..

${ }^{16}$ We exclude firm-level controls of advertising/assets, industry sales to households, and R\&D/assets to maximize the size of the sample without making assumptions for missing data. Additionally, such variables are not typically regarded as determinants of premium in the literature.
} 
significantly affect the runup period as defined by a $(-42,-1)$ window, while negatively affecting the markup in accordance with Ahern and Sosyura (2015). The net result is a negative impact on the $(-42,+5)$ premium, significant at the $1 \%$ level and contrasting with the significantly positive effect of rumors found by Chou et al. (2015) and the lack of rumor effects by Ahern and Sosyura (2015). This negative association between rumors and premiums is robust to both an alternative definition of premium and to additional controls, as evidenced in Models 4-6.

However, the average (median) time to takeover announcement is 130.14 (98) days for accurate initial rumors in our sample. We surmise that combining rumor sources from five different databases has resulted in a high degree of precision in determining the initial rumor date, and thus it appears appropriate to consider an extended runup period, despite convention on this issue. Indeed, we find that rumors are significant in determining the runup once we increase the length of this period to $(-120,-1)$ in Model 7 . Consequently, we find the premium to be unaffected by rumors in Model 8, supporting the notion that acquirers adjust bids to avoid the impact of rumors as in Ahern and Sosyura (2015). In untabulated results, this finding holds when the additional controls in Models 5 and 6 are included, when the premium is instead defined as SDC's final offer price compared to the price 120 days prior, and even when the length of the runup is changed from 120 to 180 days, although in this case the p-value for the rumor effect on the runup is 0.058 .

In Panel B, we dissect rumors by article rationale, presenting significant findings on rumor types within the table. Our full results with insignificant rumor characteristics are omitted for brevity but are available upon request. As shown in Models 1 and 2, the abnormal returns in the runup period are typically offset by opposing abnormal returns in the markup period, resulting in an insignificant effect on the premium in Model 3. However, we find two exceptions: the first is when insiders are cited as the cause of the rumor, resulting in a significantly positive premium of $18.2 \%(\mathrm{p}$-value $=0.023)$, and the second is when targets themselves initiate the rumor, resulting in a significantly negative premium of $23.8 \%$ (p-value=0.026). This latter result is consistent with 
the negative merger outcomes of target-initiated deals as identified by Aktas et al. (2010), Davis et al. (2017), and Masulis and Simsir (2017), and robust to using SDC's final offer price as the definition of a premium in Model 4 (p-value=0.001). The former result is novel, representing the only rumor type for which bidders do not appear to sufficiently adjust their bid to account for the rumor runup effect. This finding remains significant at the $5 \%$ level when using the alternate premium definition. Perhaps insiders seek to generate interest in the target firm when they believe that the market's re-evaluation of the firm's value will increase (independent of the takeover effect), or perhaps insiders are attempting to manipulate bids for their personal advantage. However, this is merely speculative, and the issue merits further investigation.

\section{Conclusions}

This paper employs a hand-collected dataset of initial ("scoop") takeover rumors, derived from a wide variety of public sources and databases including Capital IQ, Factiva, ProQuest, S\&P Takeover Talk, and Zephyr to examine the predictive power of different types of takeover rumors in forecasting actual takeovers. Through a search of approximately 30,000 newspapers, business periodicals, and newswires, we identify 2,074 first-instances of takeover rumors from 2002 to 2011. We find evidence that takeover announcements are anticipated, with accurate rumors strongly outperforming inaccurate rumors, both on and to a lesser degree prior to the rumor date, and that rumor date returns vary according to various rumor content characteristics.

When performing logistic regressions to predict the likelihood of post-rumor takeover announcements, we find that, in aggregate, rumors are negative predictors. That is, most rumors are false, in accordance with the literature. However, once rumors are classified by content, we find many rumor types to be significant positive predictors of impending takeovers, a finding that is robust to the inclusion of anticipatory controls and alternate definitions of accuracy. We find evidence that certain rumor types (those in which a financial advisor was hired by the target, an insider was cited, management needs to be improved, strong takeover synergies are specified, 
or suspicious behavior was noted) are reliable predictors of both takeovers in general as well as 'beneficial' takeovers (those yielding positive announcement period returns for target firms).

When we group rumors into those we deem ex-ante to be informative (because they contain three or more rumor rationales demonstrably linked to future takeover activity rather than based on unsubstantiated takeover chatter or an increase in call options placed on the target firm), we find that such rumors provide significantly positive rumor date $(0,+1)$ returns. Similarly, these rumors are predictive of impending takeovers (both in general and of 'beneficial' ones), with findings robust to a variety of measures. When we group rumors into those we deem ex-ante speculative (based only on takeover chatter or investors' positions in call options), we find the opposite - significantly negative returns over the rumor date and over the long-run, and having a negative predictive ability for both general and 'beneficial' takeover announcements. Most telling, the monthly returns for an equally-weighted portfolio which is long on target firms subject to Informative rumors while short on target firms subject to Speculative rumors average around $1 \%$ over the one year post-rumor period, significant at the $1 \%$ level, with highly illiquid stocks driving results and thus appearing to limit arbitrage.

Interestingly, we enter the debate on rumor premium effects by concluding that the length of the runup period employed is critical; in our sample, many initial rumors occur prior to the standard $(-41,-1)$ runup period, and their positive influence on the premium is thus ignored if this period is not extended. We also conclude that the premium may be affected by individual rumor rationales, with insiders cited within the rumor being associated with positive premiums, and the target firm initiating the rumor associated with negative premiums.

We interpret this evidence as supportive of our hypothesis that the underlying rationale justifying the release of public information has differential effects on firm share prices and predictability. In this way, we contribute to the literature on financial content analysis, share price momentum and reversal, as well as the empirical literature on takeover rumors. Berelson 
(1952:147) notes that: "Content analysis stands or falls by its categories. Particular studies have been productive to the extent that the categories were clearly formulated and well adapted to the problem and the content." We believe that such categories should reflect the catalyst behind the intended message. 


\section{References}

Agrawal, A., and T. Nasser, 2005, Insider trading in takeover targets, Journal of Corporate Finance 18, 598-625.

Ahern, K. R., and D. Sosyura, 2015, Rumor has it: Sensationalism in financial media, Review of Financial Studies 28, 2050-2093.

Aktas, N., E. de Bodt, and R. Roll, 2010, Negotiations under the threat of an auction, Journal of Financial Economics 98, 241-255.

Altman, E. I., 1968, Financial ratios, discriminant analysis and the prediction of corporate bankruptcy, Journal of Finance 23, 589-609.

Ambrose, B., and W. L. Megginson, 1992, The role of asset structure, ownership structure, and takeover defenses in determining acquisition likelihood, Journal of Financial and Quantitative Analysis 27, 575-589.

Andrade, G., M. Mitchell, and E. Stafford, 2001, New evidence and perspectives on mergers, Journal of Economic Perspectives 15, 103-120.

Asquith, P., R. F. Bruner, and D. W. Mullins, Jr., 1983, The gains to bidding firms from merger, Journal of Financial Economics 11, 121-139.

Barberis, N., A. Shleifer, and R. Vishny, 1998, A model of investor sentiment, Journal of Financial Economics 49, 307-343.

Barnes, B. G., N. L. Harp, and D. Oler, 2014, Evaluating the SDC mergers and acquisitions database, The Financial Review 49, 793-821.

Berelson, B., 1952, Content Analysis in Communication Research (The Free Press, New York).

Betton, S., B. E. Eckbo, and K. S. Thorburn, 2008, Corporate Takeovers, In Eckbo, B. E., ed., Handbook of Corporate Finance: Empirical Corporate Finance, Vol. 2. Handbooks in Finance Series (Elsevier, North-Holland, Amsterdam), 291-430.

Betton, S., B. E. Eckbo, and K. S. Thorburn, 2009, Merger negotiations and the toehold puzzle, Journal of Financial Economics 91, 158-178.

Betton, S., B. E. Eckbo, R. Thompson, and K. S, Thorburn, 2014, Merger negotiations with stock market feedback, Journal of Finance 69, 1705-1745.

Bhagat, S., M. Dong, D. Hirshleifer, and R. Noah, 2005, Do tender offers create value? New methods and evidence, Journal of Financial Economics 76, 3-60.

Bharadwaj, A., and A. Shivdasani, 2003, Valuation effects of bank financing in acquisitions, Journal of Financial Economics 67, 113-148.

Bradley, M., A. Desai, and E. H. Kim, 1988, Synergistic gains from corporate acquisitions and their division between the stockholders of target and acquiring firms, Journal of Financial Economics 21, 3-40.

Cai, J., M. H. Song, and R. A. Walkling, 2011, Anticipation, acquisitions, and bidder returns: Industry shocks and the transfer of information across rivals, Review of Financial Studies 24, 2242-2285.

Campbell, J. Y., Lo A. W., and A. C. MacKinlay, 1997, The Econometrics of Financial Markets (Princeton University Press, Princeton, New Jersey).

Chan, W. S., 2003, Stock price reaction to news and no-news: Drift and reversal after headlines, Journal of Financial Economics 70, 223-260. 
Chen, H., P. De, Y. Hu, and B-H. Hwang, 2014, Wisdom of crowds: The value of stock opinions transmitted through social media, Review of Financial Studies 27, 1367-1403.

Chou, H., G. Y. Tian, and X. Yin, 2015, Takeover rumors: Returns and pricing of rumored targets, International Review of Financial Analysis 41, 13-27.

Cornett, M. M., B. Tanyeri, and H. Tehranian, 2011, The effect of merger anticipation on bidder and target firm announcement period returns, Journal of Corporate Finance 17, 595-611.

Daniel, K., D. Hirshleifer, and A. Subrahmanyam, 1998, Investor psychology and security market under- and overreactions, Journal of Finance 53, 1839-1885.

Davis, F., T. Walker, and T. Zhou, 2017, M\&A deal initiation: The case of the unwelcome suitor, International Journal of Managerial Finance (Forthcoming).

Dimopoulos, T., and S. Sacchetto, 2014, Preemptive bidding, target resistance, and takeover premiums, Journal of Financial Economics, 114, 444-470.

Dougal, C., J. Engelberg, D. Garcia, and C. Parsons, 2012, Journalists and the stock market, Review of Financial Studies 25, 639-679.

Eckbo, B. E., 1992, Mergers and the value of antitrust deterrence, Journal of Finance 47, 1005-1029.

Engelberg, J. E., and C. A. Parsons, 2011, The causal impact of media in financial markets, Journal of Finance 66, 67-97.

Faccio, M., and R. W. Masulis, 2005, The choice of payment method in European mergers and acquisitions, Journal of Finance 60, 1345-1388.

Fang, L., and J. Peress, 2009, Media coverage and the cross-section of stock returns, Journal of Finance 64, 2023-2052.

Fuller, K., J. Netter, and M. Stegemoller, 2002, What do returns to acquiring firms tell us? Evidence from firms that make many acquisitions, Journal of Finance 57, 1763-1793.

Gao, Y., and D. Oler, 2012, Rumors and pre-announcement trading: Why sell target stocks before acquisition announcements? Review of Quantitative Finance and Accounting 39, 485-508.

Griffin, J. M., N. H. Hirschey, and P. J. Kelly, 2011, How important is the financial media in global markets? Review of Financial Studies 24, 3941-3995.

Gompers, P., J. Ishii, and A. Metrick, 2003, Corporate governance and equity prices, The Quarterly Journal of Economics 118, 107-156.

Gort, M., 1969, An economic disturbance theory of mergers, The Quarterly Journal of Economics 83, 624-642.

Guran, U. G., and A. W. Butler, 2012, Don't believe the hype: Local media slant, local advertising, and firm value, Journal of Finance 67, 561-597.

Hansen, R., 1987, A theory for the exchange medium in mergers and acquisitions, Journal of Business 60, 75-95.

Harford, J., 1999, Corporate cash reserves and acquisitions, Journal of Finance 54, 1969-1997.

Harford, J., S. A. Mansi, and W. F. Maxwell, 2008, Corporate governance and firm cash holdings in the US, Journal of Financial Economics 87, 535-555.

Hoitash, R., and M. Krishnan, 2008, Herding, momentum and investor over-reaction, Review of Quantitative Finance and Accounting 30, 25-47. 
Holmes, T. J., and J. A. Schmitz, Jr., 1995, On the turnover of business firms and business managers, Journal of Political Economy 103, 1005-1038.

Hong, H., and J. C. Stein, 1999, A unified theory of underreaction, momentum trading, and overreaction in asset markets, Journal of Finance 54, 2143-2184.

Ismail, A., 2008, Which acquirers gain more, single or multiple? Recent evidence from the USA market, Global Finance Journal 19, 72-84.

Jia, W., G. Redigolo, S. Shu, and J. Zhao, 2017, Crowd wisdom or rumor mill? The dual role of social media, Boston College working paper.

Jegadeesh, N., and D. Wu, 2013, Word power: A new approach for content analysis, Journal of Financial Economics 110, 712-729.

Jenter, D., and K. Lewellen, 2015, CEO preferences and acquisitions, Journal of Finance 70, 28132852.

Kosfeld, M., 2005, Rumours and markets, Journal of Mathematical Economics 41, 646-664.

Liberti, J. M., and M. A. Petersen, 2017, Information: Hard and soft, Northwestern University Working Paper.

Loderer, C., and K. Martin, 1990, Corporate acquisitions by listed firms: The experience of a comprehensive sample, Financial Management 19, 17-33.

Loughran, T., and B. McDonald, 2011, When is a liability not a liability? Textual analysis, dictionaries, and 10-Ks, Journal of Finance 66, 35-65.

Luo, Y., 2005, Do insiders learn from outsiders? Evidence from mergers and acquisitions, Journal of Finance 60, 1951-1978.

Ma, M., and F. Zhang, 2016, Investor reaction to merger and acquisition rumors, University of Utah Working Paper.

Maksimovic, V., and G. Phillips, 2001, The market for corporate assets: Who engages in mergers and asset sales and are there efficiency gains? Journal of Finance 56, 2019-2065.

Malatesta, P., and R. Thompson, 1985, Partially anticipated events: A model of stock price reactions with an application to corporate acquisitions, Journal of Financial Economics 14, 237-250.

Masulis, R. W., and S. A. Simsir, 2017, Deal initiation in mergers and acquisitions, Journal of Financial and Quantitative Analysis (Forthcoming).

Mitchell, M. L., and J. H. Mulherin, 1996, The impact of industry shocks on takeover and restructuring activity, Journal of Financial Economics 41, 193-229.

Mitchell, M., T. Pulvino, and E. Stafford, 2004, Price pressure around mergers, Journal of Finance 59, 31-63.

Moeller, S. B., F. P. Schlingemann, and R. M. Stulz, 2004, Firm size and the gains from acquisitions, Journal of Financial Economics 73, 201-228.

Mulherin, H., and S. A. Simsir, 2015, Measuring deal premiums in takeovers, Financial Management 44, 1-14.

Officer, M. S., 2003, Termination fees in mergers and acquisitions, Journal of Financial Economics 69, 431-467.

Palepu, K. G., 1986, Predicting takeover targets: A methodological and empirical analysis, Journal of Accounting and Economics 8, 3-35. 
Peress, J., 2014, The media and the diffusion of information in financial markets: Evidence from newspaper strikes, Journal of Finance 69, 2007-2043.

Pound, J., and R. Zeckhauser, 1990, Clearly heard on the street: The effect of takeover rumors on stock prices, Journal of Business 63, 291-308.

Purnanandam, A., and N. Seyhun, 2017, Do short-sellers trade on private information or false information? Journal of Financial and Quantitative Analysis (Forthcoming).

Rhodes-Kropf, M., and S. Viswanathan, 2004, Market valuation and merger waves, Journal of Finance 59, 2685-2718.

Rhodes-Kropf, M., D. Robinson, and S. Viswanathan, 2005, Valuation waves and merger activity: The empirical evidence, Journal of Financial Economics 77, 561-603.

Ryan, P., and R. J. Taffler, 2004, Are economically significant stock returns and trading volumes driven by firm-specific news releases? Journal of Business Finance \& Accounting 31, 49-82.

Schipper, K., and R. Thompson, 1983, Evidence on the capitalized value of merger activity for acquiring firms, Journal of Financial Economics 11, 85-119.

Schwert, G., 1996, Markup pricing in mergers and acquisitions, Journal of Financial Economics 41, $153-192$.

Shiller, R., 2005, Irrational Exuberance, 2nd Edition (Princeton University Press, Princeton, New Jersey).

Shleifer, A., and R. Vishny, 1997, The limits of arbitrage, Journal of Finance 52, 35-55.

Song M. H., and R. A. Walkling, 2000, Abnormal returns to rivals of acquisition targets: A test of the 'Acquisition Probability Hypothesis', Journal of Financial Economics 55, 143-171.

Song, M. H., and R. A. Walkling, 2011, Anticipation, acquisitions, and bidder returns: Industry shocks and the transfer of information across rivals, Review of Financial Studies 24, 2242-2285.

Tetlock, P. C., 2007, Giving content to investor sentiment: The role of media in the stock market, Journal of Finance 62, 1139-1168.

Tetlock, P. C., M. Saar-Tsechansky, and S. Macskassy, 2008, More than words: Quantifying language to measure firms' fundamentals, Journal of Finance 63, 1437-1467.

Tetlock, P. C., 2010, Does public financial news resolve asymmetric information? Review of Financial Studies 23, 3520-3557.

Tetlock, P. C., 2011, All the news that's fit to reprint: Do investors react to stale information? Review of Financial Studies 24, 1481-1512.

Zivney, T. L., W. J. Bertin, and K. M. Torabzadeh, 1996, Overreaction to takeover speculation, Quarterly Review of Economics and Finance 36, 89-115. 


\section{Table 1: Summary statistics of rumored target firms}

This table presents summary statistics of rumor articles by rumor characteristics which are not mutually-exclusive and are derived from the initial ('scoop') reporting article. Advertising/Assets and R\&D/Assets are as defined in Ahern and Sosyura (2015). Due to a large number of missing observations for these variables, they are not included in our subsequent analysis. Counts of rumor articles are displayed by time periods. Accuracy rate indicates the percentage of scoop articles in which a formal takeover bid is made for the target firm within one year, as indicated in either the SDC database or from a manual verification via the Factiva database. Target size represents the natural $\log$ of assets as per the most recent quarter prior to the rumor date. Variable definitions are provided in Appendix A. Significance at the $10 \%, 5 \%$, and $1 \%$ level is indicated by $* * *$, and $* * *$, respectively.

Panel A: Rumored target firm attributes

\begin{tabular}{lcclllrl} 
Variable & $\mathrm{N}$ & Mean & Median & Variable & $\mathrm{N}$ & Mean & Median \\
\hline Advertising/Assets (\%) & 922 & 0.037 & 0.014 & Resmismatch & 1800 & 0.510 & 1.000 \\
Cashratio & 1888 & 0.227 & 0.143 & ROA & 1886 & -0.007 & 0.009 \\
Changesize2y & 1830 & 0.290 & 0.119 & Salesgrowth2y & 1823 & 0.373 & 0.131 \\
Concentration & 1901 & 0.563 & 0.533 & Salesshock & 1899 & 0.115 & 0.079 \\
Dormancy & 2074 & 2.633 & 0.100 & SalesshockSq & 1899 & 0.019 & 0.006 \\
Infoasymm & 1845 & 0.061 & 0.000 & Shareturnover & 1867 & 0.617 & 0.741 \\
Prevmergers & 2074 & 0.988 & 0.000 & Size & 1899 & 7.362 & 7.556 \\
Priorreturn2y & 1980 & 0.370 & 0.016 & Tobin's Q & 1899 & 1.006 & 1.000 \\
R\&D/Assets (\%) & 1295 & 0.099 & 0.055 & Valuable Brand $(\%)$ & 2074 & 14.513 & 0.000 \\
\hline
\end{tabular}

Panel B: Rumored target firm attributes, by rumor characteristics

\begin{tabular}{lcccccc}
$\quad$ Rumor & $2002-$ & $2008-$ & $2010-$ & & Target & Accuracy \\
characteristics & 2007 & 2009 & 2011 & Total & size & rate \\
\hline AdvisorHired & 111 & 66 & 62 & 239 & 5.86 & 41.8 \\
AnalystReport & 270 & 147 & 200 & 617 & 7.65 & 16.5 \\
BidderMentioned & 397 & 239 & 259 & 895 & 7.72 & 26.3 \\
BlockPurchase & 32 & 16 & 21 & 69 & 7.19 & 27.5 \\
FinancingSource & 15 & 12 & 12 & 39 & 7.61 & 41.0 \\
IndustryActivity & 119 & 73 & 66 & 258 & 7.79 & 21.3 \\
InsiderCited & 140 & 60 & 91 & 291 & 7.70 & 44.3 \\
MgmtConcerns & 29 & 9 & 11 & 49 & 7.27 & 40.8 \\
OptionsIncreased & 62 & 137 & 286 & 485 & 7.86 & 9.9 \\
PEFundInvolved & 125 & 42 & 81 & 248 & 7.80 & 32.7 \\
SynergyCited & 36 & 24 & 24 & 84 & 7.59 & 44.0 \\
TakeoverChatter & 62 & 172 & 335 & 569 & 7.65 & 9.8 \\
TargetDistress & 59 & 27 & 6 & 92 & 6.70 & 38.0 \\
TargetInitiated & 183 & 104 & 75 & 362 & 5.72 & 33.7 \\
Undervalued & 148 & 107 & 121 & 376 & 7.69 & 19.9 \\
UnusualActivity & 18 & 9 & 13 & 40 & 7.86 & 30.0 \\
BidderDenied & 16 & 7 & 3 & 26 & 8.96 & 30.8 \\
TargetDenied & 7 & 6 & 1 & 14 & 8.88 & 42.9 \\
Informative & 281 & 124 & 132 & 537 & 7.51 & 37.6 \\
Speculative & 10 & 85 & 249 & 344 & 7.63 & 6.7 \\
\hline All rumored firms & 738 & 555 & 781 & 2,074 & 7.36 & 20.9
\end{tabular}

Panel C: Distribution by industry

Fama-French 17 Industry Classification

\begin{tabular}{lr}
\hline Food & 71 \\
Mining \& Minerals & 69 \\
Oil \& Petroleum & 161 \\
Textiles, Apparel, Footware & 33 \\
Consumer Durables & 28 \\
Chemicals & 32 \\
Drugs, Soap, Perfumes, Tobacco & 140 \\
Construction \& Constr. Materials & 50 \\
Steel Works, Etc. & 58 \\
Fabricated Products & 1 \\
Machinery \& Business Equipment & 263 \\
Automobiles & 24 \\
Transportation & 66 \\
Utilities & 8 \\
Retail Stores & 176 \\
Banks, Ins. Firms, \& Financials & 36 \\
Other (Services, Wholesale, etc.) & 858 \\
\hline
\end{tabular}




\section{Table 2: Rumored target abnormal event returns}

This table reports cumulative average abnormal returns (CAARs) for firms rumored to be targets. The abnormal returns are market model value-weighted returns and are reported in percentages. Rumors that came true are those in which an official takeover announcement was made within one year of the first report of the rumor in the press. Panel A reports CAARs during a $(0,+1)$ window immediately surrounding the rumor date (day 0). Panel B reports CAARs during the runup period $(-20,-2)$, while Panel C focuses on the post-rumor period $(+2,+20)$. Panel D reports CAARs over the whole event period $(-20,+20)$. The results of a difference of means ttest (based on true rumor CAARs vs. false rumor CAARs) are presented in the final column. P-values based on clustered standard errors are reported in parentheses. Variable definitions are provided in Appendix A. Significance at the 10\%, 5\%, and 1\% level is indicated by $*, * *$, and $* * *$, respectively.

Rumor came true
All
Yes
No
Difference

Panel A: Rumor publication date CAARs $(0,+1)$

\begin{tabular}{|c|c|c|c|c|c|c|c|c|}
\hline All & $3.81^{* * *}$ & $(0.000)$ & $8.37^{* * *}$ & $(0.000)$ & $2.62^{* * * *}$ & $(0.000)$ & $5.75^{* * *}$ & $(0.000)$ \\
\hline AdvisorHired & $5.92^{* * * *}$ & $(0.000)$ & $9.45^{* * *}$ & $(0.000)$ & $3.38^{* * * *}$ & $(0.006)$ & $6.07^{* * * *}$ & $(0.000)$ \\
\hline AnalystReport & $3.10^{* * *}$ & $(0.000)$ & $7.30^{* *}$ & $(0.011)$ & $2.26^{* * *}$ & $(0.000)$ & $5.04^{*}$ & $(0.079)$ \\
\hline BidderMentioned & $5.75^{* * * *}$ & $(0.000)$ & $10.99^{* * *}$ & $(0.000)$ & $3.94^{* * *}$ & $(0.000)$ & $7.05^{* * *}$ & $(0.000)$ \\
\hline BlockPurchase & $7.49^{* * *}$ & $(0.007)$ & 15.17 & (0.104) & $4.49^{* * *}$ & $(0.001)$ & 10.68 & $(0.246)$ \\
\hline FinancingSource & $10.25^{* * *}$ & $(0.011)$ & $15.98^{*}$ & $(0.080)$ & $6.09^{* * * *}$ & $(0.017)$ & 9.90 & $(0.278)$ \\
\hline IndustryActivity & $4.22^{* * *}$ & $(0.000)$ & $6.35^{* * *}$ & $(0.000)$ & $3.66^{* * *}$ & $(0.000)$ & $2.69^{* *}$ & $(0.025)$ \\
\hline InsiderCited & $7.33^{* * *}$ & $(0.000)$ & $10.53^{* * *}$ & $(0.000)$ & $4.90^{* * *}$ & $(0.000)$ & $5.63^{* * *}$ & $(0.000)$ \\
\hline MgmtConcerns & $5.24^{* * *}$ & $(0.001)$ & $6.39^{* * *}$ & $(0.003)$ & $4.45^{*}$ & $(0.059)$ & 1.94 & $(0.509)$ \\
\hline OptionsIncreased & $2.68^{* * *}$ & $(0.000)$ & $5.11^{* * *}$ & $(0.000)$ & $2.42^{* * *}$ & $(0.000)$ & $2.69^{* * *}$ & $(0.003)$ \\
\hline PEFundInvolved & $6.26^{* * *}$ & $(0.000)$ & $11.18^{* * *}$ & $(0.000)$ & $3.89^{* * * *}$ & $(0.000)$ & $7.29^{* * *}$ & $(0.001)$ \\
\hline SynergyCited & $9.04^{* * *}$ & $(0.017)$ & $16.01^{*}$ & $(0.067)$ & $4.04^{* * *}$ & $(0.018)$ & 11.98 & $(0.174)$ \\
\hline TakeoverChatter & $2.73^{* * *}$ & $(0.000)$ & $5.15^{* * *}$ & $(0.000)$ & $2.47^{* * *}$ & $(0.000)$ & $2.69^{*}$ & $(0.055)$ \\
\hline TargetDistress & -0.72 & $(0.769)$ & 2.57 & $(0.613)$ & -2.77 & $(0.258)$ & 5.34 & $(0.174)$ \\
\hline TargetInitiated & $3.07^{* * * *}$ & $(0.000)$ & $7.40^{* * * *}$ & $(0.000)$ & 0.86 & $(0.451)$ & $6.53^{* * * *}$ & $(0.000)$ \\
\hline Undervalued & $3.70^{* * *}$ & $(0.000)$ & $6.17^{* * *}$ & $(0.000)$ & $3.09^{* * * *}$ & $(0.000)$ & $3.70^{* * * *}$ & $(0.001)$ \\
\hline UnusualActivity & 1.49 & $(0.529)$ & 1.61 & $(0.821)$ & 1.43 & $(0.331)$ & 0.18 & (0.981) \\
\hline BidderDenied & 1.79 & $(0.218)$ & 5.32 & $(0.134)$ & 0.12 & $(0.930)$ & 5.21 & $(0.158)$ \\
\hline TargetDenied & $6.31^{* *}$ & $(0.020)$ & 1.74 & $(0.489)$ & $9.48^{* *}$ & $(0.023)$ & $-7.84^{*}$ & $(0.067)$ \\
\hline Informative & $6.18^{* * *}$ & $(0.000)$ & $10.23^{* * *}$ & $(0.000)$ & $3.78^{* * * *}$ & $(0.000)$ & $6.45^{* * * *}$ & $(0.001)$ \\
\hline Speculative & $1.80^{* * * *}$ & $(0.000)$ & 3.63 & $(0.145)$ & $1.67^{* * * *}$ & $(0.000)$ & 1.96 & $(0.424)$ \\
\hline
\end{tabular}

Panel B: Runup period CAARs $(-20,-2)$

\begin{tabular}{lcccccccc}
\hline All & -0.04 & $(0.930)$ & $2.33^{* *}$ & $(0.034)$ & -0.65 & $(0.151)$ & $2.98^{* * *}$ & $(0.012)$ \\
AdvisorHired & 0.71 & $(0.684)$ & $6.28^{* *}$ & $(0.024)$ & -3.31 & $(0.131)$ & $9.58^{* * *}$ & $(0.007)$ \\
AnalystReport & 0.25 & $(0.677)$ & 2.53 & $(0.214)$ & -0.21 & $(0.725)$ & 2.73 & $(0.197)$ \\
BidderMentioned & 0.34 & $(0.545)$ & 1.27 & $(0.307)$ & 0.02 & $(0.971)$ & 1.25 & $(0.371)$ \\
BlockPurchase & 1.50 & $(0.477)$ & -1.49 & $(0.645)$ & 2.67 & $(0.316)$ & -4.16 & $(0.319)$ \\
FinancingSource & 0.05 & $(0.982)$ & -1.00 & $(0.742)$ & 0.81 & $(0.771)$ & -1.81 & $(0.658)$ \\
IndustryActivity & 1.76 & $(0.109)$ & 2.84 & $(0.486)$ & 1.49 & $(0.106)$ & 1.35 & $(0.746)$ \\
InsiderCited & $2.32^{* *}$ & $(0.028)$ & $4.59^{* *}$ & $(0.011)$ & 0.59 & $(0.639)$ & $4.01^{*}$ & $(0.066)$ \\
MgmtConcerns & 0.64 & $(0.785)$ & 0.81 & $(0.409)$ & 0.53 & $(0.870)$ & 0.29 & $(0.952)$ \\
OptionsIncreased & $-2.02^{* * *}$ & $(0.010)$ & -3.53 & $(0.136)$ & $-1.85^{* *}$ & $(0.025)$ & -1.67 & $(0.500)$ \\
PEFundInvolved & 1.05 & $(0.235)$ & 1.32 & $(0.399)$ & 0.93 & $(0.392)$ & 0.39 & $(0.834)$ \\
SynergyCited & $4.19^{*}$ & $(0.095)$ & 8.54 & $(0.105)$ & 1.06 & $(0.611)$ & 7.48 & $(0.183)$ \\
TakeoverChatter & -1.21 & $(0.130)$ & -1.53 & $(0.633)$ & -1.17 & $(0.150)$ & 0.36 & $(0.913)$ \\
TargetDistress & -0.12 & $(0.971)$ & 3.76 & $(0.493)$ & -2.48 & $(0.532)$ & 6.24 & $(0.355)$ \\
TargetInitiated & 0.31 & $(0.835)$ & 2.83 & $(0.258)$ & -0.98 & $(0.592)$ & 3.82 & $(0.219)$ \\
Undervalued & $-1.79^{*}$ & $(0.057)$ & -1.90 & $(0.395)$ & $-1.76^{*}$ & $(0.089)$ & 0.14 & $(0.954)$ \\
UnusualActivity & $7.32^{*}$ & $(0.089)$ & 19.12 & $(0.146)$ & 1.87 & $(0.356)$ & 17.25 & $(0.190)$ \\
BidderDenied & $-8.35^{*}$ & $(0.098)$ & -23.75 & $(0.161)$ & -2.00 & $(0.378)$ & -21.74 & $(0.195)$ \\
TargetDenied & -7.28 & $(0.285)$ & -4.67 & $(0.217)$ & -8.77 & $(0.425)$ & 4.10 & $(0.712)$
\end{tabular}

Page $\mid 38$ 
$\begin{array}{lllllllll}\text { Informative } & 0.40 & (0.636) & 2.19 & (0.184) & -0.65 & (0.484) & 2.84 & (0.133)\end{array}$

$\begin{array}{lllllllll}\text { Speculative } & -1.83^{*} & (0.059) & -0.38 & (0.935) & -1.93^{* *} & (0.050) & 1.55 & (0.747)\end{array}$

Panel C: Post-rumor period CAARs $(+2,+20)$

\begin{tabular}{lcccccccc}
\hline All & -0.45 & $(0.285)$ & 0.87 & $(0.378)$ & $-0.79^{*}$ & $(0.089)$ & 1.66 & $(0.127)$ \\
AdvisorHired & 1.47 & $(0.493)$ & 2.09 & $(0.373)$ & 1.02 & $(0.757)$ & 1.07 & $(0.791)$ \\
AnalystReport & 0.23 & $(0.688)$ & 1.77 & $(0.241)$ & -0.08 & $(0.891)$ & 1.86 & $(0.254)$ \\
BidderMentioned & -0.12 & $(0.841)$ & 0.08 & $(0.947)$ & -0.20 & $(0.785)$ & 0.28 & $(0.847)$ \\
BlockPurchase & 0.71 & $(0.613)$ & 5.45 & $(0.117)$ & -1.15 & $(0.412)$ & $6.60^{*}$ & $(0.078)$ \\
FinancingSource & -1.07 & $(0.578)$ & -1.35 & $(0.679)$ & -0.87 & $(0.721)$ & -0.47 & $(0.907)$ \\
IndustryActivity & -0.37 & $(0.706)$ & -1.86 & $(0.531)$ & 0.02 & $(0.985)$ & 1.88 & $(0.548)$ \\
InsiderCited & 0.39 & $(0.713)$ & 1.72 & $(0.359)$ & -0.62 & $(0.618)$ & 2.34 & $(0.298)$ \\
MgmtConcerns & -1.23 & $(0.641)$ & 1.47 & $(0.767)$ & -3.06 & $(0.307)$ & 4.53 & $(0.432)$ \\
OptionsIncreased & -1.78 & $(0.011)$ & 0.58 & $(0.771)$ & $-2.04^{* * *}$ & $(0.006)$ & 2.62 & $(0.217)$ \\
PEFundInvolved & $1.75^{* *}$ & $(0.035)$ & $3.86^{* *}$ & $(0.015)$ & 0.73 & $(0.448)$ & $3.13^{*}$ & $(0.089)$ \\
SynergyCited & -1.72 & $(0.232)$ & -2.37 & $(0.381)$ & -1.24 & $(0.424)$ & -1.12 & $(0.716)$ \\
TakeoverChatter & $-2.66^{* * *}$ & $(0.000)$ & -3.11 & $(0.248)$ & $-2.61^{* * *}$ & $(0.000)$ & -0.50 & $(0.858)$ \\
TargetDistress & 1.67 & $(0.621)$ & -4.51 & $(0.356)$ & 5.51 & $(0.226)$ & -10.02 & $(0.132)$ \\
TargetInitiated & 1.49 & $(0.383)$ & 1.58 & $(0.519)$ & 1.44 & $(0.524)$ & 0.14 & $(0.967)$ \\
Undervalued & -0.89 & $(0.338)$ & 3.21 & $(0.267)$ & $-1.91^{* *}$ & $(0.036)$ & $5.11^{*}$ & $(0.093)$ \\
UnusualActivity & -0.72 & $(0.761)$ & 0.44 & $(0.946)$ & -1.26 & $(0.533)$ & 1.69 & $(0.800)$ \\
BidderDenied & $-9.91^{* *}$ & $(0.044)$ & -23.21 & $(0.121)$ & -3.66 & $(0.106)$ & -19.55 & $(0.182)$ \\
TargetDenied & -0.35 & $(0.939)$ & -7.58 & $(0.253)$ & 4.81 & $(0.458)$ & -12.39 & $(0.162)$ \\
Informative & 0.77 & $(0.428)$ & 1.01 & $(0.520)$ & 0.62 & $(0.612)$ & 0.38 & $(0.847)$ \\
Speculative & $-2.79^{* * * *}$ & $(0.000)$ & -3.30 & $(0.145)$ & $-2.76^{* * *}$ & $(0.001)$ & -0.54 & $(0.820)$ \\
\hline
\end{tabular}

Panel D: Complete period CAARs $(-20,+20)$

\begin{tabular}{|c|c|c|c|c|c|c|c|}
\hline All & $3.95^{* * *}(0.000)$ & $12.71^{* * *}$ & $(0.000)$ & $1.68^{* *}$ & $(0.026)$ & $11.03^{* * *}$ & $(0.000)$ \\
\hline AdvisorHired & $9.01^{* * *}(0.002)$ & $19.21^{* * *}$ & $(0.000)$ & 1.67 & $(0.664)$ & $17.54^{* * *}$ & $(0.001)$ \\
\hline AnalystReport & $4.06^{* * *}(0.000)$ & $13.51^{* * *}$ & $(0.009)$ & $2.19^{* *}$ & $(0.023)$ & $11.32^{* * *}$ & $(0.006)$ \\
\hline BidderMentioned & $7.15^{* * * *}(0.000)$ & $13.96^{* * *}$ & $(0.000)$ & $4.79^{* * *}$ & $(0.000)$ & $9.17^{* * *}$ & $(0.001)$ \\
\hline BlockPurchase & $11.26^{* * *}(0.002)$ & $19.81^{* * *}$ & $(0.010)$ & $7.91^{* *}$ & $(0.046)$ & 11.90 & $(0.139)$ \\
\hline FinancingSource & $15.20^{* * *}(0.004)$ & $15.42^{* *}$ & $(0.026)$ & $15.04^{* *}$ & $(0.050)$ & 0.38 & (0.969) \\
\hline Industry Activity & $6.48^{* * *}(0.000)$ & 8.30 & $(0.115)$ & $6.01^{* * * *}$ & $(0.000)$ & 2.28 & $(0.676)$ \\
\hline InsiderCited & $11.06^{* * *}(0.000)$ & $18.22^{* * *}$ & $(0.000)$ & $5.59^{* * *}$ & $(0.003)$ & $12.62^{* * *}$ & $(0.000)$ \\
\hline MgmtConcerns & $4.14 \quad(0.418)$ & 6.48 & $(0.485)$ & 2.55 & $(0.673)$ & 3.93 & $(0.720)$ \\
\hline OptionsIncreased & $(0.561)$ & 3.98 & $(0.361)$ & -1.25 & $(0.340)$ & 5.22 & $(0.251)$ \\
\hline PEFundInvolved & $10.07^{* * *}(0.000)$ & $17.19^{* * *}$ & $(0.000)$ & $6.67^{* * * *}$ & $(0.000)$ & $10.52^{* * * *}$ & $(0.002)$ \\
\hline SynergyCited & $12.41^{* *} \quad(0.017)$ & $24.42^{* *}$ & $(0.028)$ & 3.79 & $(0.343)$ & $20.63^{*}$ & $(0.078)$ \\
\hline TakeoverChatter & $-0.62 \quad(0.620)$ & 2.69 & $(0.587)$ & -0.97 & $(0.448)$ & 3.65 & $(0.475)$ \\
\hline TargetDistress & $(0.739)$ & 1.67 & $(0.827)$ & 1.75 & $(0.802)$ & -0.08 & $(0.994)$ \\
\hline TargetInitiated & $5.76^{* *}(0.027)$ & $12.45^{* * *}$ & $(0.002)$ & 2.34 & $(0.484)$ & $10.11^{* *}$ & $(0.050)$ \\
\hline Undervalued & $2.03 \quad(0.226)$ & $8.48^{* *}$ & $(0.039)$ & 0.42 & $(0.816)$ & $8.06^{*}$ & $(0.071)$ \\
\hline UnusualActivity & $8.44^{*} \quad(0.066)$ & $21.46^{*}$ & $(0.056)$ & 2.43 & $(0.571)$ & $19.03^{*}$ & $(0.100)$ \\
\hline BidderDenied & $-14.27^{*}(0.059)$ & -33.27 & $(0.187)$ & -6.45 & $(0.115)$ & -26.82 & $(0.278)$ \\
\hline TargetDenied & $1.33 \quad(0.875)$ & -3.84 & $(0.616)$ & 4.29 & $(0.747)$ & -8.13 & $(0.587)$ \\
\hline Informative & $8.79^{* * * *}(0.000)$ & $14.53^{* * *}$ & $(0.000)$ & $5.42^{* * * *}$ & $(0.002)$ & $9.10^{* * * *}$ & $(0.007)$ \\
\hline Speculative & $-2.58^{*} \quad(0.057)$ & 1.10 & $(0.845)$ & $-2.85^{* *}$ & $(0.042)$ & 3.95 & $(0.498)$ \\
\hline
\end{tabular}




\section{Table 3: Multivariate analysis of target firm cumulative abnormal returns on the rumor date}

This table reports coefficient estimates for a series of OLS regressions of target firm cumulative abnormal returns (CARs) on a number of explanatory variables. CARs are calculated as the sum of value-weighted market-model abnormal returns for target firms over days $(0,+1)$ relative to the initial rumor date (day 0). Variable definitions are provided in Appendix A. Firm fixed effects include Cashratio, Changesize2y, Concentration, Dormancy, Infoasymm, Prevmergers, Priorreturn2y, Resmismatch, ROA, Salesgrowth2y, Salesshock, SalesshockSq, and Shareturnover. Industry fixed effects are based on the Fama-French 17 industry classifications. News article fixed effects are created using all media sources with at least five scoop articles. Rumor fixed effects refer to individual rumor types that we found to be insignificant and thus omitted for brevity: BidderDenied, BlockPurchase, FinancingSource, IndustryActivity, MgmtConcerns, OptionsIncreased, PEFundInvolved, SynergyCited, TakeoverChatter, TargetDenied, TargetInitiated, Undervalued, and UnusualActivity. P-values based on clustered standard errors are reported in parentheses. Significance at the $10 \%, 5 \%$, and $1 \%$ level is indicated by ***, and ***, respectively.

\begin{tabular}{|c|c|c|c|c|c|c|c|c|}
\hline & $\begin{array}{c}(1) \\
\text { CAR } \\
(0,+1)\end{array}$ & & $\begin{array}{c}(2) \\
\text { CAR } \\
(0,+1)\end{array}$ & & $\begin{array}{c}(3) \\
\text { CAR } \\
(0,+1)\end{array}$ & & $\begin{array}{c}(4) \\
\text { CAR } \\
(0,+1) \\
\end{array}$ & \\
\hline AdvisorHired & $0.037^{* * * *}$ & $(0.009)$ & & & & & & \\
\hline AnalystReport & $-0.012^{*}$ & $(0.082)$ & & & & & & \\
\hline BidderMentioned & $0.029^{* * *}$ & $(0.000)$ & & & & & & \\
\hline InsiderCited & $0.026^{* *}$ & $(0.028)$ & & & & & & \\
\hline TargetDistress & $-0.060^{* * *}$ & $(0.005)$ & & & & & & \\
\hline Rumor CAR(-5, -1) & -0.046 & $(0.408)$ & & & -0.038 & $(0.500)$ & -0.039 & $(0.488)$ \\
\hline Rumor CAR $(-41,-1)$ & 0.001 & $(0.944)$ & & & 0.004 & $(0.851)$ & 0.001 & $(0.979)$ \\
\hline EstAnnReturn & 0.057 & $(0.297)$ & & & 0.078 & $(0.198)$ & 0.062 & $(0.296)$ \\
\hline ValuableBrand & -0.0037 & $(0.769)$ & & & 0.011 & $(0.316)$ & 0.014 & $(0.190)$ \\
\hline Informative & & & $0.024^{* * *}$ & $(0.003)$ & $0.026^{\text {*** }}$ & $(0.003)$ & $0.017^{* *}$ & $(0.036)$ \\
\hline Speculative & & & $-0.015^{* *}$ & $(0.013)$ & $-0.016^{* * *}$ & $(0.008)$ & $-0.013^{* *}$ & $(0.027)$ \\
\hline Accurate & & & & & & & $0.051^{* * *}$ & $(0.000)$ \\
\hline Firm FE & Yes & & No & & Yes & & Yes & \\
\hline Ind/Year FE & No & & Yes & & No & & No & \\
\hline News FE & Yes & & Yes & & Yes & & Yes & \\
\hline Rumor FE & Yes & & No & & No & & No & \\
\hline Constant & -0.017 & $(0.800)$ & -0.005 & $(0.874)$ & -0.037 & $(0.595)$ & -0.076 & $(0.293)$ \\
\hline $\mathrm{N}$ & 1694 & & 2015 & 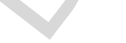 & 1694 & & 1694 & \\
\hline Adj. $R^{2}$ & 0.08 & & 0.04 & & 0.05 & & 0.07 & \\
\hline F-test (p-value) & 0.000 & & 0.000 & & 0.000 & & 0.000 & \\
\hline
\end{tabular}




\section{Table 4: Rumor accuracy}

This table examines the relationship between rumor characteristics and the likelihood that a rumor comes true. Panel A, columns 1-4, present fixed effect logit regression results in which the dependent variable is a dummy variable equal to one if a merger rumor came true within one year of the initial rumor date, as indicated in either the SDC database or from a manual search of the Factiva database, and zero otherwise. Panel B is similar to Panel A, but adds the condition that target firm returns over days $(-41,+1)$ relative to the takeover announcement date must be positive for the rumor to be considered accurate. Variable definitions are provided in Appendix A. Firm fixed effects include Cashratio, Changesize2y, Concentration, Dormancy, Infoasymm, Prevmergers, Priorreturn2y, Resmismatch, ROA, Salesgrowth2y, Salesshock, SalesshockSq, Shareturnover, and Size. Industry fixed effects are based on the FamaFrench 17 industry classifications. News article fixed effects are created using all media sources with at least five scoop articles. Rumor fixed effects refer to individual rumor types that we found to be insignificant and thus omitted for brevity: AnalystReport, BidderDenied, BlockPurchase, FinancingSource, IndustryActivity, OptionsIncreased, PEFundInvolved, and TakeoverChatter. Pvalues based on clustered standard errors are reported in parentheses. Significance at the $10 \%, 5 \%$, and $1 \%$ level is indicated by $*$, **, and $* * *$, respectively.

$\underline{\text { Panel A: Rumor characteristics leading to takeover announcements within one year }}$

\begin{tabular}{|c|c|c|c|c|c|c|c|c|}
\hline & $\begin{array}{c}(1) \\
\text { Accurate }\end{array}$ & & $\begin{array}{c}(2) \\
\text { Accurate }\end{array}$ & & $\begin{array}{c}\text { (3) } \\
\text { Accurate }\end{array}$ & & $\begin{array}{c}\text { (4) } \\
\text { Accurate }\end{array}$ & \\
\hline AdvisorHired & $0.615^{* * *}$ & $(0.009)$ & $0.675 * * *$ & $(0.003)$ & & & & \\
\hline BidderMentioned & $0.334 * *$ & $(0.047)$ & $0.371 * *$ & $(0.027)$ & & & & \\
\hline InsiderCited & $0.879 * * *$ & $(0.000)$ & $0.882 * * *$ & $(0.000)$ & & & & \\
\hline MgmtConcerns & $0.820 * * *$ & $(0.010)$ & $0.781 * *$ & $(0.013)$ & & & & \\
\hline SynergyCited & $1.026 * * *$ & $(0.001)$ & $1.032 * * *$ & $(0.000)$ & & & & \\
\hline TargetDenied & 0.727 & $(0.379)$ & 0.707 & $(0.391)$ & & & & \\
\hline TargetDistress & $0.693^{* *}$ & $(0.036)$ & $0.659^{* *}$ & $(0.048)$ & & & & \\
\hline TargetInitiated & $0.548 * *$ & $(0.048)$ & $0.512 *$ & $(0.061)$ & & & & \\
\hline Undervalued & $0.340^{*}$ & $(0.080)$ & $0.347 *$ & $(0.073)$ & & & & \\
\hline UnusualActivity & $0.712^{* *}$ & $(0.050)$ & $0.745^{* *}$ & $(0.041)$ & & & & \\
\hline Size & $-0.132 * *$ & $(0.013)$ & $-0.160 * * *$ & $(0.003)$ & & & $-0.147 * * *$ & $(0.003)$ \\
\hline Rumor CAR $(0,+1)$ & $3.373 * * *$ & $(0.000)$ & & $\infty$ & & & $3.752 * * *$ & $(0.000)$ \\
\hline Rumor CAR $(-5,-1)$ & 0.008 & $(0.992)$ & 0.034 & $(0.968)$ & & & 0.123 & $(0.886)$ \\
\hline Rumor CAR(-41, -1) & $0.446^{*}$ & $(0.075)$ & $0.412 *$ & $(0.099)$ & & & $0.554 * *$ & $(0.028)$ \\
\hline ValuableBrand & $-0.462 * *$ & $(0.047)$ & $-0.460 * *$ & $(0.045)$ & & & $-0.464 * *$ & $(0.029)$ \\
\hline EstDealLikelihood & & & $0.400 * * *$ & $(0.000)$ & & & & \\
\hline Informative & & & & & $0.885 * * *$ & $(0.000)$ & $0.929 * * *$ & $(0.000)$ \\
\hline Speculative & & & & & $-0.857 * * *$ & $(0.000)$ & $-0.567 * *$ & $(0.027)$ \\
\hline Ind/News/Year FE & Yes & & Yes & & Yes & & Yes & \\
\hline Firm FE & Yes & & Yes & & No & & Yes & \\
\hline Rumor FE & Yes & & Yes & & No & & No & \\
\hline Constant & 1.365 & $(0.225)$ & 1.669 & $(0.135)$ & $-2.361 * * *$ & $(0.000)$ & $2.233 * *$ & $(0.043)$ \\
\hline $\mathrm{N}$ & 1667 & & 1667 & & 2004 & & 1667 & \\
\hline Pseudo $\mathrm{R}^{2}$ & 0.189 & & 0.182 & & 0.100 & & 0.166 & \\
\hline$\chi^{2}$-test ( $p$-value) & 0.000 & & 0.000 & & 0.000 & & 0.000 & \\
\hline
\end{tabular}


Panel B: Rumor characteristics leading to 'beneficial' takeover announcements within one year

Accurate

AdvisorHired

BidderMentioned

InsiderCited

MgmtConcerns

SynergyCited

TargetDenied

TargetDistress

TargetInitiated

Undervalued

UnusualActivity

Size

Rumor $\operatorname{CAR}(0,+1)$

Rumor CAR(-5, -1)

Rumor CAR(-41, -1)

ValuableBrand

EstDealLikelihood

Informative

Speculative

Ind/News/Year FE

Firm FE

Rumor FE

Constant

$\mathrm{N}$

pseudo $\mathrm{R}^{2}$

$\chi^{2}$-test (p-value)
(1)

(2)

Accurate

$0.821^{* * *} \quad(0.003) \quad 0.864^{* * *}$

0.256

$0.686^{* * *}$

$1.234^{\text {*** }}$

0.482

$1.905^{* *}$

$-0.205$

0.0875

$-0.193$

$1.081^{* *}$

$-0.181^{* * *}$

$2.646^{* * *}$

$2.293^{* *}$

$0.872^{* * *}$

$-0.624^{*}$

$(0.210)$

$(0.003)$

(0.001)

(0.141)

$(0.045)$

$(0.596)$

$(0.797)$

(0.478)

(0.011)

(0.004)

(0.000)

(0.013)

$(0.001)$

(0.058)

0.285
0.681

$1.183^{* * *}$

0.481

$1.919^{* *}$

$-0.211$

0.055

$-0.186$

$1.109^{* *}$

$-0.206^{* * *}$

$2.251^{* *}$

$0.853^{* * *}$

$-0.618^{*}$

$0.353^{* * *}$

Yes

Yes

Yes

2.039

1667

0.202

0.000

(0.144) 2.256
(3)

Accurate (0.002)

$(0.158)$

$(0.004)$

(0.002)

(0.139)

(0.041)

(0.586)

(0.872)

(0.494)

(0.011)

(0.001)

(0.013)

(0.002)

$(0.055)$

(0.006)

$\begin{array}{llll}0.521^{* * *} & (0.001) & 0.560^{* * *} & (0.003)\end{array}$

$-1.059^{* * *}(0.001)-0.736^{* *} \quad(0.028)$

Yes Yes

No Yes

No No

$(0.110)$

$-2.699$

$(0.000)$

2004

0.083

0.000
(4) Accurate 
Table 5: Long-short portfolio returns

This table reports monthly returns from an equally-weighted long-short portfolio by strategy. The first strategy, Rumor Characteristics, establishes a long position in targets of rumors with significant prediction power for rumor accuracy and a short position in rumors with no significant prediction power, as based on the prediction accuracy of rumor characteristics using logit model 1 in Table 4, Panel A. We exclude target firms with non-mutually exclusive rumor rationales. The second strategy, Rumor Informativeness, establishes a long position in Informative target firms and a short position in Speculative target firms. Amihud illiquidity is calculated as per Amihud (2002) and Ahern and Sosyura (2015): average $\left(\left|r_{t}\right| /\right.$ Volume $\left._{t}\right)$. The proportional bid-ask spread is calculated as $100 *($ ask-bid)/M, where $\mathrm{M}$ is the midpoint of the bid and ask, using closing prices from CRSP. Low and High refer to observations relative to the median for each subsample. Firms are added to the portfolio on day 2 after the rumor is published, and are held for up to one year, with monthly rebalancing. If less than five firms meet the criteria for the long or short portfolio, the long/short portfolio return is assumed to be zero. We use the market model with the CRSP value weighted market return as a benchmark. The monthly returns presented here are the daily returns compounded over a period of 20 days. Newey and West (1987) p-values are reported in parentheses. We follow Newey and West (1994) to compute lags. Significance at the $1 \%, 5 \%$, and $10 \%$ level is indicated by $* * *, * *$, and $*$, respectively.

\section{Portfolio Strategy}

\begin{tabular}{|c|c|c|c|c|}
\hline & \multirow[t]{2}{*}{ All } & \multicolumn{2}{|c|}{ Amihud Illiquidity } & \multirow{2}{*}{$\begin{array}{c}\text { Proportional } \\
\text { bid-ask spread } \\
\text { Low High }\end{array}$} \\
\hline & & Low & High & \\
\hline Rumor Characteristics & $\begin{array}{l}1.057 * * * \\
(0.007)\end{array}$ & $\begin{array}{l}0.080 \\
(0.354)\end{array}$ & $\begin{array}{l}0.788 * * \\
(0.029)\end{array}$ & $\begin{array}{ll}0.401 & 1.097 * * * \\
(0.157) & (0.010)\end{array}$ \\
\hline Rumor Informativeness & $\begin{array}{l}1.089 * * * \\
(0.008)\end{array}$ & $\begin{array}{l}-0.582 \\
(0.529)\end{array}$ & $\begin{array}{l}0.321 * * \\
(0.048)\end{array}$ & $\begin{array}{cc}0.276 & 0.719 \\
(0.824) & (0.222)\end{array}$ \\
\hline
\end{tabular}




\section{Table 6: Multivariate analysis of rumored bidder firm cumulative abnormal returns}

This table reports coefficient estimates for a series of OLS regressions of cumulative abnormal returns (CARs) for firms rumored to be potential bidders on a number of explanatory variables. CARs are calculated as the sum of value-weighted market-model abnormal returns for bidders relative to the initial rumor date (day 0). Variable definitions are provided in Appendix A. Firm fixed effects include Cashratio, Changesize2y, Concentration, Dormancy, Infoasymm, Prevmergers, Priorreturn2y, Resmismatch, ROA, Salesgrowth2y, Salesshock, SalesshockSq, and Shareturnover. News article fixed effects are created using all media sources with at least five scoop articles. Rumor fixed effects refer to individual rumor types that we found to be insignificant and thus omitted for brevity: AdvisorHired, AnalystReport, FinancingSource, IndustryActivity, OptionsIncreased, TargetInitiated, Undervalued, and UnusualActivity. P-values based on clustered standard errors are reported in parentheses. Significance at the 10\%, 5\%, and 1\% level is indicated by $*, * *$, and $* * *$, respectively.

(1)

(2)

(3)

\begin{tabular}{lllllll} 
& \multicolumn{2}{c}{$\begin{array}{c}\text { RumoredBidder } \\
\text { CAR }(-20,-2)\end{array}$} & \multicolumn{2}{c}{ RumoredBidder } & \multicolumn{2}{c}{$\begin{array}{c}\text { RumoredBidder } \\
\text { CAR }(0,+1)\end{array}$} \\
\cline { 2 - 7 } BidderDenied & -0.022 & $(0.513)$ & $0.022^{*}$ & $(0.051)$ & -0.030 & $(0.573)$ \\
BlockPurchase & $0.056^{* *}$ & $(0.012)$ & -0.003 & $(0.871)$ & 0.054 & $(0.122)$ \\
InsiderCited & 0.003 & $(0.836)$ & $-0.008^{*}$ & $(0.099)$ & 0.007 & $(0.641)$ \\
MgmtConcerns & -0.021 & $(0.360)$ & 0.006 & $(0.356)$ & $-0.042^{*}$ & $(0.071)$ \\
PEFundInvolved & 0.001 & $(0.966)$ & $0.014^{* *}$ & $(0.030)$ & -0.011 & $(0.532)$ \\
SynergyCited & $0.022^{* *}$ & $(0.023)$ & 0.000 & $(0.993)$ & 0.002 & $(0.903)$ \\
TakeoverChatter & $0.033^{* * *}$ & $(0.001)$ & -0.003 & $(0.374)$ & 0.001 & $(0.950)$ \\
TargetDenied & 0.010 & $(0.577)$ & $-0.018^{*}$ & $(0.067)$ & -0.039 & $(0.351)$ \\
TargetDistress & 0.001 & $(0.987)$ & $0.019^{* *}$ & $(0.043)$ & -0.017 & $(0.519)$ \\
Accurate & 0.009 & $(0.346)$ & 0.001 & $(0.890)$ & -0.020 & $(0.102)$ \\
EstAnnReturn_B & 0.054 & $(0.415)$ & $0.065^{* *}$ & $(0.012)$ & 0.044 & $(0.563)$ \\
ValuableBrand & 0.012 & $(0.143)$ & -0.002 & $(0.493)$ & 0.001 & $(0.886)$ \\
RumoredBidderCAR(-5,-1) & & & -0.042 & $(0.339)$ & 0.095 & $(0.376)$ \\
News FE & Yes & & Yes & & Yes & \\
Rumor FE & Yes & & Yes & & Yes & \\
Constant & $0.095^{*}$ & $(0.083)$ & 0.012 & $(0.585)$ & 0.055 & $(0.412)$ \\
\hline N & 568 & & 568 & & 568 & \\
Adj. R ${ }^{2}$ & 0.04 & & 0.03 & & -0.01 & \\
F-test (p-value) & 0.000 & & 0.000 & & 0.201 & \\
\hline
\end{tabular}


Table 7: Target firm runup, markup, and premium relative to the announcement date

This table presents fixed effect OLS regression results of cumulative abnormal stock returns and premiums of merger targets in various windows measured relative to the announcement date as recorded in SDC. Observations include mergers of public U.S. targets that were announced between 2002 and 2011 seeking a change in majority ownership. Offer Premium represents the final offer premium from SDC (truncated at $-100 \%$ and 200\%) as suggested by Officer (2003) and Jenter and Lewellen (2015), among others. Deal characteristics include Completed, MajorityCash, TenderOffer, LBO, CrossBorder, and TargetDefenses, as defined in Ahern and Sosyura (2015). Firm-level controls include past year's sales growth, target size (log of market equity), Tobin's Q ((total assetscommon equity + market equity)/total assets), and a dummy for a valuable brand. Rumor fixed effects in Panel B refer to individual rumor types that we found to be insignificant and thus omitted for brevity: AnalystReport, BidderDenied, BidderMentioned, FinancingSource, IndustryActivity, MgmtConcerns, OptionsIncreased, PEFundInvolved, TakeoverChatter, TargetDenied, Undervalued, and UnusualActivity. Variable definitions are provided in Appendix A. P-values based on clustered standard errors are reported in parentheses. Significance at the $10 \%, 5 \%$, and $1 \%$ level is indicated by *,**, and ***, respectively.

$\underline{\text { Panel A: Effect of rumor existence on runup, markup, and premium }}$

\begin{tabular}{|c|c|c|c|c|c|c|c|c|}
\hline & $\begin{array}{l}(1) \\
\text { CAR } \\
(-42,-1)\end{array}$ & $\begin{array}{l}(2) \\
\text { CAR } \\
(0,+5)\end{array}$ & $\begin{array}{l}(3) \\
\text { CAR } \\
(-42,+5)\end{array}$ & $\begin{array}{l}(4) \\
\text { Offer } \\
\text { Premium }\end{array}$ & $\begin{array}{l}(5) \\
\text { CAR } \\
(-42,+5)\end{array}$ & $\begin{array}{l}(6) \\
\text { Offer } \\
\text { Premium }\end{array}$ & $\begin{array}{l}(7) \\
\text { CAR } \\
(-120,-1)\end{array}$ & $\begin{array}{l}(8) \\
\text { CAR } \\
(-120,+5)\end{array}$ \\
\hline Rumor & $\begin{array}{l}0.028 \\
(0.185)\end{array}$ & $\begin{array}{l}-0.125^{\text {*** }} \\
(0.000)\end{array}$ & $\begin{array}{l}-0.094^{* * * *} \\
(0.001)\end{array}$ & $\begin{array}{l}-0.072^{* * *} \\
(0.009)\end{array}$ & $\begin{array}{l}-0.097^{* * *} \\
(0.000)\end{array}$ & $\begin{array}{l}-0.074^{* * *} \\
(0.007)\end{array}$ & $\begin{array}{l}0.085^{* *} \\
(0.050)\end{array}$ & $\begin{array}{l}-0.034 \\
(0.447)\end{array}$ \\
\hline AcqPublic & & & & & $\begin{array}{l}0.058^{* *} \\
(0.011)\end{array}$ & $\begin{array}{l}0.057^{* * *} \\
(0.007)\end{array}$ & & \\
\hline AcqTermFee & & & & & $\begin{array}{l}-0.024 \\
(0.189)\end{array}$ & $\begin{array}{l}-0.002 \\
(0.935)\end{array}$ & & \\
\hline Friendly & & & & & $\begin{array}{l}0.068 \\
(0.164)\end{array}$ & $\begin{array}{l}0.022 \\
(0.742)\end{array}$ & & \\
\hline ROA & & & & & $\begin{array}{l}-0.117^{* *} \\
(0.046)\end{array}$ & $\begin{array}{l}-0.003 \\
(0.939)\end{array}$ & & \\
\hline TarTermFee & & & & & $\begin{array}{l}0.098^{* * * *} \\
(0.001)\end{array}$ & $\begin{array}{l}0.073^{* * *} \\
(0.005)\end{array}$ & & \\
\hline Deal Characteristics & Yes & Yes & & Yes & Yes & Yes & Yes & Yes \\
\hline Firm-level Controls & Yes & Yes & Yes & Yes & Yes & Yes & Yes & Yes \\
\hline Ind/Year FE & Yes & Yes & Yes & Yes & Yes & Yes & Yes & Yes \\
\hline Constant & $\begin{array}{l}-0.240^{*} \\
(0.069)\end{array}$ & $\begin{array}{l}0.393^{* * *} \\
(0.001)\end{array}$ & $\begin{array}{l}0.141 \\
(0.442)\end{array}$ & $\begin{array}{l}0.489^{* * * *} \\
(0.005)\end{array}$ & $\begin{array}{l}-0.047 \\
(0.813)\end{array}$ & $\begin{array}{l}0.274 \\
(0.139)\end{array}$ & $\begin{array}{l}-0.207 \\
(0.378)\end{array}$ & $\begin{array}{l}0.177 \\
(0.509)\end{array}$ \\
\hline $\mathrm{N}$ & 1815 & 1815 & 1815 & 1750 & 1815 & 1750 & 1815 & 1815 \\
\hline Adj. $R^{2}$ & 0.037 & 0.126 & 0.121 & 0.109 & 0.141 & 0.118 & 0.044 & 0.090 \\
\hline F-test (p-value) & 0.000 & 0.000 & 0.000 & 0.000 & 0.000 & 0.000 & 0.000 & 0.000 \\
\hline
\end{tabular}


$\underline{\text { Panel B: Effect of individual rumor types on runup, markup, and premium }}$

\begin{tabular}{|c|c|c|c|c|}
\hline & $\begin{array}{l}(1) \\
\text { CAR } \\
(-120,-1)\end{array}$ & $\begin{array}{l}(2) \\
\text { CAR } \\
(0,+5) \\
\end{array}$ & $\begin{array}{l}(3) \\
\text { CAR } \\
(-120,+5)\end{array}$ & $\begin{array}{l}(4) \\
\text { Offer } \\
\text { Premium }\end{array}$ \\
\hline AdvisorHired & $\begin{array}{l}0.225^{* *} \\
(0.041)\end{array}$ & $\begin{array}{l}-0.134^{* * *} \\
(0.001)\end{array}$ & $\begin{array}{l}0.095 \\
(0.377)\end{array}$ & $\begin{array}{l}-0.085 \\
(0.154)\end{array}$ \\
\hline BlockPurchase & $\begin{array}{l}-0.028 \\
(0.825)\end{array}$ & $\begin{array}{l}0.160^{* *} \\
(0.036)\end{array}$ & $\begin{array}{l}0.136 \\
(0.210)\end{array}$ & $\begin{array}{l}0.027 \\
(0.689)\end{array}$ \\
\hline InsiderCited & $\begin{array}{l}0.214^{\text {****}} \\
(0.009)\end{array}$ & $\begin{array}{l}-0.032 \\
(0.393)\end{array}$ & $\begin{array}{l}0.182^{* *} \\
(0.023)\end{array}$ & $\begin{array}{l}0.102^{* *} \\
(0.046)\end{array}$ \\
\hline SynergyCited & $\begin{array}{l}0.066 \\
(0.697)\end{array}$ & $\begin{array}{l}-0.142^{* *} \\
(0.049)\end{array}$ & $\begin{array}{l}-0.078 \\
(0.641)\end{array}$ & $\begin{array}{l}-0.064 \\
(0.471)\end{array}$ \\
\hline TargetDistress & $\begin{array}{l}0.176 \\
(0.127)\end{array}$ & $\begin{array}{l}-0.132^{* *} \\
(0.021)\end{array}$ & $\begin{array}{l}0.050 \\
(0.658)\end{array}$ & $\begin{array}{l}-0.103 \\
(0.188)\end{array}$ \\
\hline TargetInitiated & $\begin{array}{l}-0.162^{*} \\
(0.098)\end{array}$ & $\begin{array}{l}-0.085^{* *} \\
(0.033)\end{array}$ & $\begin{array}{l}-0.238^{* *} \\
(0.026)\end{array}$ & $\begin{array}{l}-0.186^{* * *} \\
(0.001)\end{array}$ \\
\hline AcqPublic & $\begin{array}{l}0.022 \\
(0.472)\end{array}$ & $\begin{array}{l}0.019 \\
(0.302)\end{array}$ & $\begin{array}{l}0.048 \\
(0.152)\end{array}$ & $\begin{array}{l}0.056^{* *} \\
(0.015)\end{array}$ \\
\hline AcqTermFee & $\begin{array}{l}0.018 \\
(0.457)\end{array}$ & $\begin{array}{l}-0.048^{* * *} \\
(0.001)\end{array}$ & $\begin{array}{l}-0.030 \\
(0.261)\end{array}$ & $\begin{array}{l}-0.029 \\
(0.124)\end{array}$ \\
\hline Friendly & $\begin{array}{l}0.088 \\
(0.255)\end{array}$ & $\begin{array}{l}0.060 \\
(0.127)\end{array}$ & $\begin{array}{l}0.148^{*} \\
(0.075)\end{array}$ & $\begin{array}{l}0.062 \\
(0.215)\end{array}$ \\
\hline ROA & $\begin{array}{l}-0.061 \\
(0.419)\end{array}$ & $\begin{array}{l}-0.071^{*} \\
(0.058)\end{array}$ & $\begin{array}{l}-0.117 \\
(0.186)\end{array}$ & $\begin{array}{l}-0.122^{* * *} \\
(0.041)\end{array}$ \\
\hline TarTermFee & $\begin{array}{l}0.084^{* *} \\
(0.026)\end{array}$ & $\begin{array}{l}0.056^{* * *} \\
(0.006)\end{array}$ & $\begin{array}{l}0.160^{* * *} \\
(0.000)\end{array}$ & $\begin{array}{l}0.093^{* * *} \\
(0.001)\end{array}$ \\
\hline Deal Characteristics & Yes & Yes & Yes & Yes \\
\hline Firm-level Controls & Yes & Yes & Yes & Yes \\
\hline Ind/Year FE & Yes & Yes & Yes & Yes \\
\hline Rumor FE & Yes & Yes & Yes & Yes \\
\hline Constant & $\begin{array}{l}-0.379 \\
(0.107) \\
\end{array}$ & $\begin{array}{l}0.283^{* *} \\
(0.025)\end{array}$ & $\begin{array}{l}-0.122 \\
(0.657)\end{array}$ & $\begin{array}{l}-0.007 \\
(0.970) \\
\end{array}$ \\
\hline $\mathrm{N}$ & 1815 & 1815 & 1815 & 1750 \\
\hline $\operatorname{Adj} . R^{2}$ & 0.052 & 0.138 & 0.109 & 0.141 \\
\hline F-test ( $p$-value) & 0.000 & 0.000 & 0.000 & 0.000 \\
\hline
\end{tabular}


Figure 1: Rumored Target Firm Average Abnormal Returns

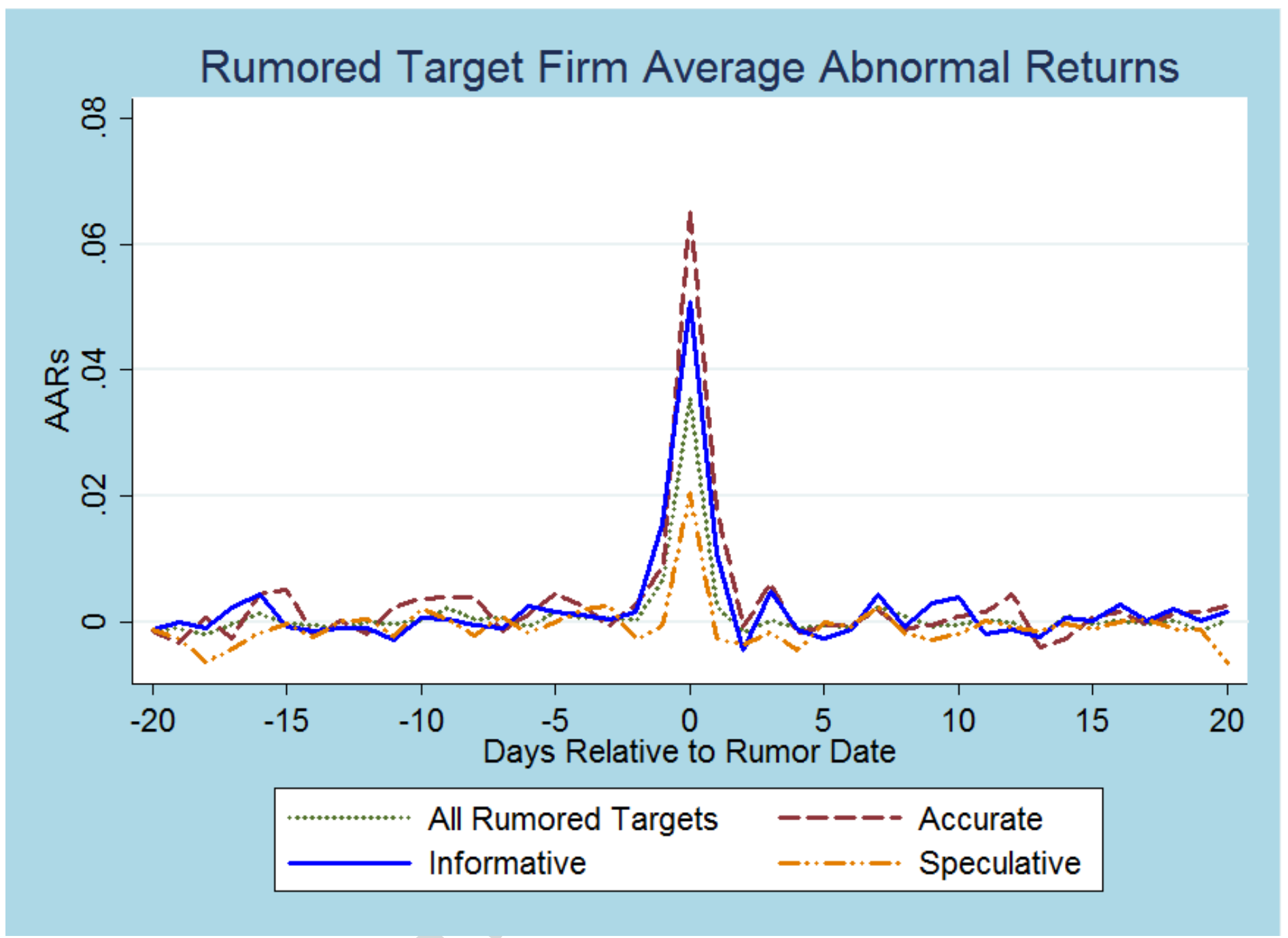




\section{Appendix A Variable Definitions}

Rumor content characteristics

AdvisorHired

Rumor indicates that the target firm has retained the services of an investment bank or

financial advisor

AnalystReport

Rumor is the result of one or more analysts reasoning that a takeover seems logical

BidderDenied

Rumor indicates that a potential bidding firm denies that parties are in negotiations

BidderMentioned

Rumor indicates the name of one or more potential bidders

BlockPurchase

Rumo

FinancingSource

Rumor provides substantial details as to how financing for the deal would occur

IndustryActivity

Rumor indicates either a competitor is being taken over or that the target industry appears ripe

for takeovers

Informative

InsiderCited

Rumors based on at least three rumor justifications, excluding those labelled as speculative

MgmtConcerns

OptionsIncreased

Rumor predicated on an anonymous source

Rumor indicates concerns with the current management

Rumor specifically mentions that an increase in call options is indicative of an impending takeover

PEFundInvolved

Rumor indicates that a private equity or hedge fund has expressed interest in a potential takeover deal

Speculative

Rumors based solely on either takeover chatter or an increase in option activity in the target firm, with no further justification provided

SynergyCited Rumor indicates that the target firm has specific attributes that would provide unique synergies to an acquirer

TakeoverChatter Rumor provides few details, yet mentions that the target firm is subject to ongoing takeover chatter

TargetDenied

TargetDistress

Rumor indicates that the target firm denies that parties are in negotiations

TargetInitiated

Undervalued

Rumor indicates that the target firm has been experiencing substantial financial and/or operating distress

UnusualActivity

Rumor has been initiated by the target firm itself

Rumor indicates that the target firm may be seen as undervalued, prompting takeover interest

Rumor indicates that something unusual has occurred which has led to takeover speculation (e.g. two CEOs simultaneously absent from conference, or other changes in executive team schedules or habits)

\section{Other variables}

Accurate

The rumored target firm becomes subject to a formal takeover announcement within one calendar year after the initial rumor date (Ahern and Sosyura, 2015)

Cashratio

Changesize2y

Concentration

Dormancy

The ratio of cash and marketable securities to marketable assets (Cornett et al., 2011)

The percentage change in the firm's total assets over the previous two years (Cornett et al., 2011)

The ratio of sales of the largest four firms to total three-digit SIC industry sales (Cornett et al., 2011)

EstAnnReturn

The number of months since the last merger in the same three-digit SIC industry (Cornett et al., 2011)

The expected announcement return of the target firm if a takeover announcement does come true, estimated from a linear regression of target announcement day returns on target size, industry, and year fixed effects in a sample of 2,342 official merger announcements of public targets over the period from 2002 to 2011 as provided by the SDC database (Ahern and Sosyura, 2015)

EstAnnReturn_B The expected announcement return of the rumored bidding firm if a takeover announcement does come true, estimated from a linear regression of bidder announcement day returns on bidder size, industry, and year fixed effects in a sample of 2,342 official merger announcements over the period from 2002 to 2011 as provided by the SDC database

EstDealLikelihood The rumor date target firm return divided by the EstAnnReturn (Ahern and Sosyura, 2015) Infoasymm An indicator variable equal to one if a firm's stock price is both overvalued (with a market-to- 
Prevmergers

Priorreturn2y

Resmismatch

ROA

Salesgrowth2y

Salesshock

SalesshockSq

Shareturnover

Size

ValuableBrand book value greater than the industry median) and opaque (share turnover is lower than the industry median) (Cornett et al., 2011)

Counts the number of times a firm proposes or receives a merger bid in the prior two years (Cornett et al., 2011)

The change in a firm's stock price in the two years prior to a given quarter (Cornett et al., 2011)

An indicator variable equal to one if i) sales growth for a firm in the last two years is less than the industry median and the long-term debt ratio (the ratio of the book value of long-term debt to total assets) is greater than the industry median, or ii) if sales growth in the last two years is greater than the industry median and the long-term debt ratio is less than the industry median, and zero otherwise (Cornett et al., 2011)

The ratio of net income before extraordinary (or nonrecurring) items to total assets (Cornett et al., 2011)

The percentage change in the firm's sales over the previous two years (Cornett et al., 2011) The absolute value of the difference between the two-year median industry sales growth rate and the two-year median sales growth rate of all sample target firms (Cornett et al., 2011) The square of sales shock (Cornett et al., 2011)

The ratio of the number of shares of stock traded for the firm to total shares outstanding (Cornett et al., 2011)

The natural log of total assets as per the most recent quarter prior to the rumor date (Cornett et al., 2011)

An indicator variable representing target firm inclusion in a list of the top 100 brands from the marketing consultancy firms Interbrand and BrandZ anytime between 2002 and 2011 (Ahern and Sosyura, 2015) 


\section{Highlights}

- Takeover rumor rationales significantly predict future takeover announcements

- Market reversal following takeover rumors depends on rumor article characteristics

- Not all takeover rumors are good news for the target firm

- Rumors providing multiple linkages to potential takeovers appear more credible

- Rumor characteristics as well as the length of the runup period affect bid prices 